Revue des patrimoines

\title{
Les grands pressoirs bourguignons pré- industriels : essai de chrono-typologie
}

\section{Bernard Lauvergeon}

\section{(2) OpenEdition}

Journals

Édition électronique

URL : http://journals.openedition.org/insitu/2447

DOI : 10.4000/insitu.2447

ISSN : 1630-7305

\section{Éditeur}

Ministère de la culture

\section{Référence électronique}

Bernard Lauvergeon, « Les grands pressoirs bourguignons pré-industriels : essai de chrono-typologie », In Situ [En ligne], 5 | 2004, mis en ligne le 17 février 2012, consulté le 19 avril 2019. URL : http:// journals.openedition.org/insitu/2447 ; DOI : 10.4000/insitu.2447

Ce document a été généré automatiquement le 19 avril 2019

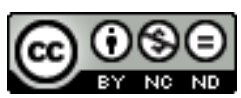

In Situ Revues des patrimoines est mis à disposition selon les termes de la licence Creative Commons Attribution - Pas d'Utilisation Commerciale - Pas de Modification 4.0 International. 


\title{
Les grands pressoirs bourguignons pré-industriels : essai de chrono- typologie
}

\author{
Bernard Lauvergeon
}

1 Cet article est le prolongement des recherches qui ont été réalisées à la Direction Régionale des Affaires Culturelles de Bourgogne par les services de l'Inventaire et de l'Ethnologie sur le patrimoine viti-vinicole bourguignon. Outre plusieurs enquêtes consacrées à l'architecture et au mobilier viticoles, ces études thématiques conjointes ont permis de repérer un pourcentage significatif des grands pressoirs pré-industriels qui subsistent aujourd'hui en Bourgogne. Plusieurs de ces machines ont d'ailleurs été l'objet tout récemment, à notre demande, d'une inscription à l'Inventaire supplémentaire des Monuments historiques.

2 Aussi proposons-nous un inventaire rapide des grands pressoirs bourguignons sous la forme d'une approche chrono-typologique. Seront analysés les trois types principaux, mais aussi les variantes qui ont été identifiées en Bourgogne, du Mâconnais au Chablisien, depuis la fin du Moyen Age jusqu'à la période contemporaine, puisque certains pressoirs ont fonctionné jusqu'au milieu du XXe siècle.

3 Cet inventaire typologique porte sur les structures des machines étudiées plus que sur l'histoire des bâtiments auxquels elles sont associées, la construction des cuveries étant souvent bien antérieure à celle des pressoirs qu'elles abritent, car ces derniers ont été très souvent restaurés voire entièrement refaits. Les archives qui ont pu être exploitées confirment les analyses que nous avons faites sur le terrain : ces machines, soumises à des forces importantes et exposées à la pourriture, étaient continuellement réparées quand ce n'étaient pas le levier ou la vis qui éclataient sous l'effet d'une pression excessive. (voir à ce propos "Le clos de Chenôve..., page 26). C'est dire que les pressoirs qui nous sont parvenus ont souvent été en grande partie reconstruits. D'ailleurs, aucune des nombreuses dates que nous avons relevées n'est antérieure au XVIII ${ }^{e}$ siècle.

On l'aura compris, la datation de ces machines est souvent malaisée, les éléments “datants ", tels que décors et inscriptions, étant, de surcroît, exceptionnels. 
5 En outre, les documents disponibles sont rares et parfois difficiles à exploiter. Le seul moyen fiable donnant une indication chronologique précise reste, dans la plupart des cas, l'analyse dendrochronologique qui peut fournir, pour certaines pièces de bois, la date d'abattage de l'arbre. Ainsi, on sait aujourd'hui, grâce aux analyses du laboratoire de Chrono-Ecologie de Besançon, que plusieurs pièces des bâtis des pressoirs du Clos de Chenôve ont été réalisées avec des arbres abattus au printemps de l'année 1449. C'est d'ailleurs la date la plus ancienne actuellement attestée pour l'ensemble des pressoirs étudiés.

Figure 1

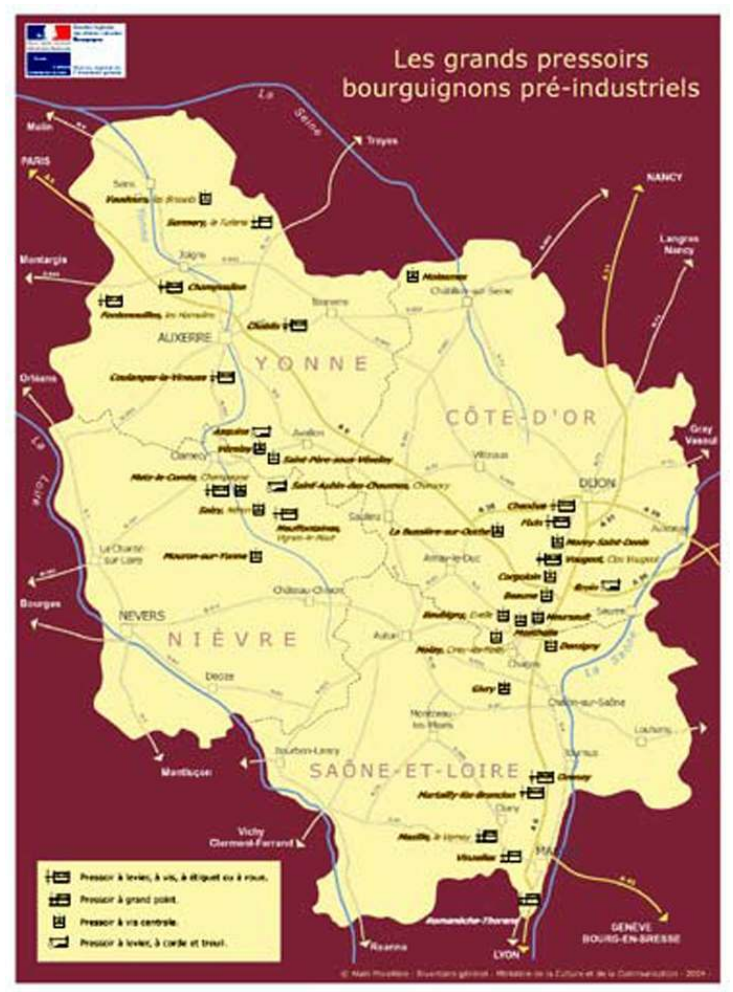

Carte de la Bourgogne. Localisation des grands pressoirs Carte A. Morelière (c) Inventaire général, 2004

Ces machines, dont la typologie est assez complexe, peuvent toutefois être regroupées en trois grandes “familles" bien distinctes, qui apparaissent d'ailleurs à des époques différentes et dont chacune est assez bien localisée : les pressoirs à levier utilisés en Côted'Or, dans les Vaux d'Yonne et l'Auxerrois, les pressoirs dits “à grand point" du Mâconnais et les pressoirs à vis centrale des Côtes de Beaune et de Nuits, mais aussi des Vaux d'Yonne et du Vézelien (fig. $\mathbf{n}^{\circ} \mathbf{1}$ ).

7 A ces trois grands types, il convient d'ajouter une forme archaïque du pressoir à levier, généralement appelée pressoir à perche ou pressoir à levier, à corde sur treuil. Il s'agit généralement de pressoirs domestiques, de dimensions modestes et de faible rendement. Ces pressoirs équipaient les petites exploitations vouées à la poly-viticulture. Ils ont laissé peu de témoins. Ils seront étudiés en fin d'exposé car leur structure, très particulière, ne permet pas de les associer aux grands pressoirs à levier traditionnels. 


\section{Les pressoirs à levier}

Conçus comme d'énormes "écrasoirs" en raison de la masse importante de leur levier, ces grands pressoirs furent utilisés dès le Moyen Age dans les châteaux, les abbayes et les grands domaines. Ils sont constitués d'un lourd bâti contreventé, assemblé au sol sur un soubassement, le chantier, et d'un levier monoxyle ou non tiré par une ([vis]: $\left.{ }^{*} V i s^{*}\right)$. Le pied de la vis est retenu au sol par une ou plusieurs pièces de bois, appelées ([taissons]: ${ }^{*}$ Taisson*). Ces derniers sont scellés profondément, lestés ou encore ancrés dans une fosse maçonnée. Une perche, l'étiquet, ou une roue munie de chevilles, ou taquets, permet d'actionner la vis. Pour éviter que l'arrière du pressoir ne se soulève pendant la presse, le chantier est scellé, lesté ou encore ancré dans le mur de la cuverie. C'est ce type de pressoir qui apparaît le plus tôt en Bourgogne.

\section{Les pressoirs à levier, à taissons enterrés, à vis actionnée par une perche, ou " étiquet"}

9 En raison de l'archaïsme de leur fonctionnement, ils sont très vraisemblablement parmi les plus anciens pressoirs à levier. Outre la structure massive du bâti et l'énorme masse de certains leviers constitués de plusieurs troncs juxtaposés, leur vis a la particularité d'être actionnée par des ([étiquets]: *Etiquet*), longues perches de frêne, amovibles, engagées dans la mortaise traversante située à la base de la vis, la ([lanterne] : *anterne*). Soumises à d'importantes forces de torsion, les lanternes étaient renforcées par des cerclages en fer forgé pour éviter qu'elles n'éclatent pendant la pressée. Comparé aux autres systèmes de serrage, l'étiquet présentait, en raison de sa relative fragilité, de nombreux inconvénients. La perche se brisait régulièrement, quand ce n'était pas la lanterne qui éclatait ou la vis qui se tordait. 
Figure 2

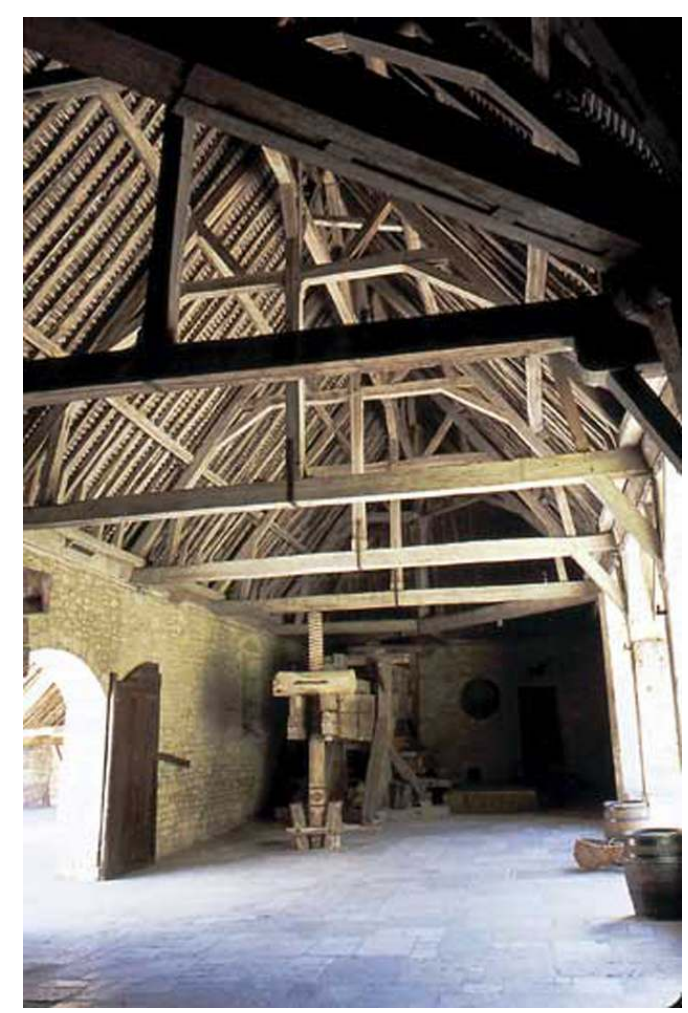

La cuverie du château du Clos de Vougeot, Côte-d'Or. Charpente et pressoir

Phot. Inv. M. Thierry @ Inventaire général, ADAGP, 2003

Les comptes des ducs de Bourgogne conservés aux archives départementales de la Côted'Or sont éloquents à ce sujet. Quand ce n'était pas la vis du pressoir qu'il fallait changer parce qu'elle éclatait ou parce qu'elle était rompue par pourriture, c'est un arbre de treuil (un levier) qui se brisait. Bien que minutieusement inspectés, nettoyés et graissés, ces pressoirs exigeaient de fréquentes interventions des charpentiers, autant avant les vendanges que pendant les pressées.

11 Les quatre énormes machines du Clos de Vougeot (Côte-d'Or) sont les exemples les plus spectaculaires, sinon les plus anciens, de ces grands pressoirs à levier et taissons enterrés qui sont attestés dès le Moyen Age. Très restaurées, peut-être ne sont-elles pas antérieures à la reconstruction partielle du château par Dom Loisier, au milieu du XVIe siècle. Quoi qu'il en soit, leur archaïsme pourrait justifier une datation plus ancienne. Ces quatre pressoirs à levier occupent les angles d'une vaste cuverie de plan carré (fig. $\mathbf{n}^{\circ} \mathbf{2}$ ), ouverte au centre. De même type, et apparemment semblables, ils ne sont pourtant ni rigoureusement identiques, ni contemporains ; c'est en tout cas ce que suggère l'analyse attentive de leur structure. 
Figure 3

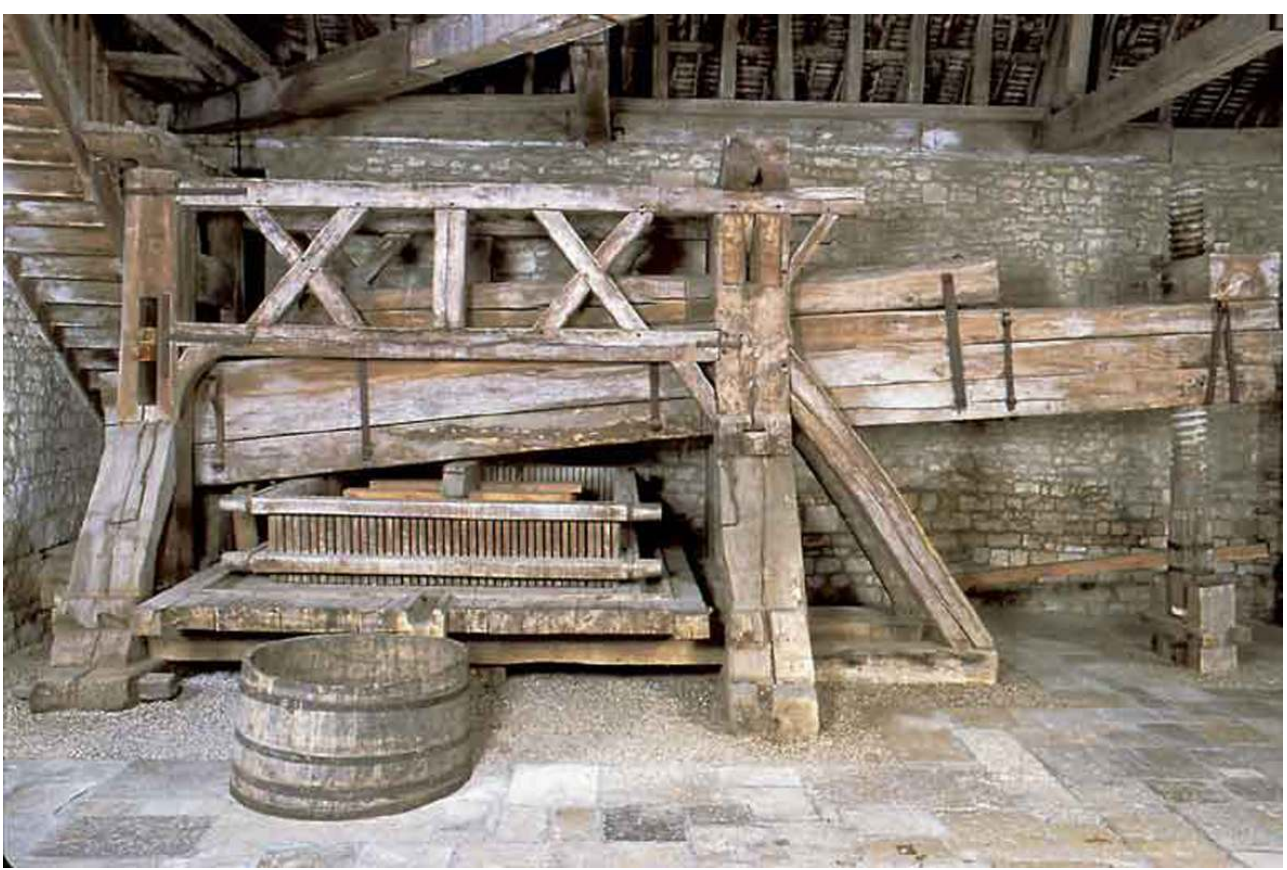

Pressoir à levier du Clos de Vougeot. Vue d'ensemble

Phot. Inv. M. Thierry @ Inventaire général, ADAGP, 2003

Le pressoir (fig. $\mathbf{n}^{\circ}$ 3), dont nous donnons la photographie, est situé dans l'angle antérieur droit de la cuverie ; c'est un des plus puissants. Son levier de 9,50 m de long est constitué de six troncs de chêne juxtaposés et renforcés par deux troncs supplémentaires placés sur l'extrados que solidarisent de puissants fers plats. En outre, avec une surface qui dépasse $16 \mathrm{~m}^{2}$, sa ([maie] : *Maie*) est la plus importante de toutes avec celle du plus grand des pressoirs du Clos de Chenôve. 
Figure 4

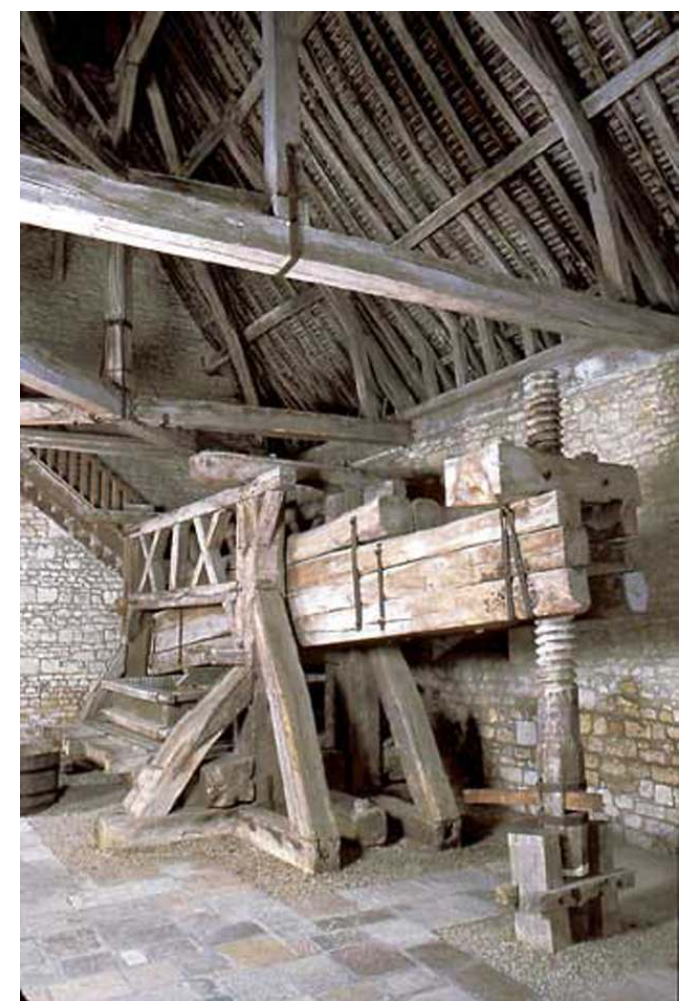

Pressoir à levier du Clos de Vougeot. Vue de trois-quarts Phot. Inv. M. Thierry @ Inventaire général, ADAGP, 2003

Toutes les pièces de bois sont surdimensionnées et la masse des leviers est impressionnante, leur section avoisinant $1 \mathrm{~m}^{2}$ (fig. $\left.\mathrm{n}^{\circ} 4\right)$.

L'([écrou]: *Ecrou*) de la vis est fixé au levier par des fers plats afin de permettre la remontée du levier lors des opérations de chargement et de déchargement de la maie, le relevage s'effectuant en desserrant la vis (fig. $\mathbf{n}^{\circ} 5$ ).

Pour éviter que les taissons ne soient arrachés, ces derniers, bloqués au mortier de chaux, sont enterrés très profondément, de $5 \mathrm{~m}$, d'après $\mathrm{P}$. Latour qui fut témoin de la réfection des taissons de l'une de ces machines (fig. $\mathbf{n}^{\circ} \mathbf{6}$ ). L'arrière du pressoir est lui aussi ancré solidement dans le mur de la cuverie. Par sécurité, l'ancrage est ici renforcé par deux pièces de chêne scellées dans le mur, qui travaillent en compression (fig. $\mathbf{n}^{\circ}$ 7). 
Figure 5

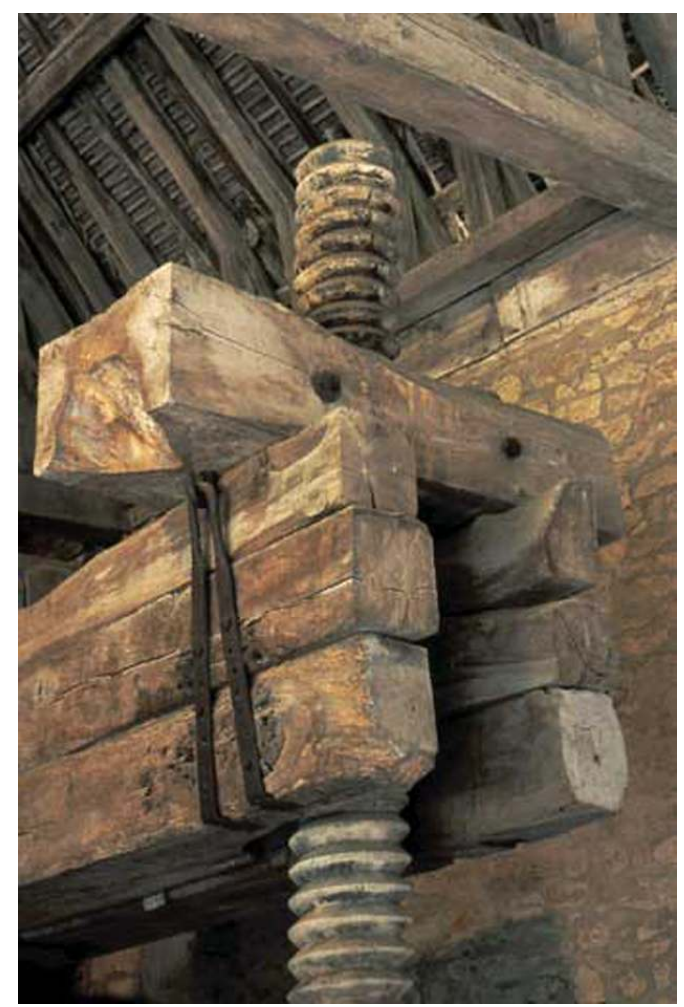

Pressoir à levier du Clos de Vougeot. L'avant du levier, la vis et l'écrou, détail Phot. Inv. M. Thierry (c) Inventaire général, ADAGP, 2003 
Figure 6

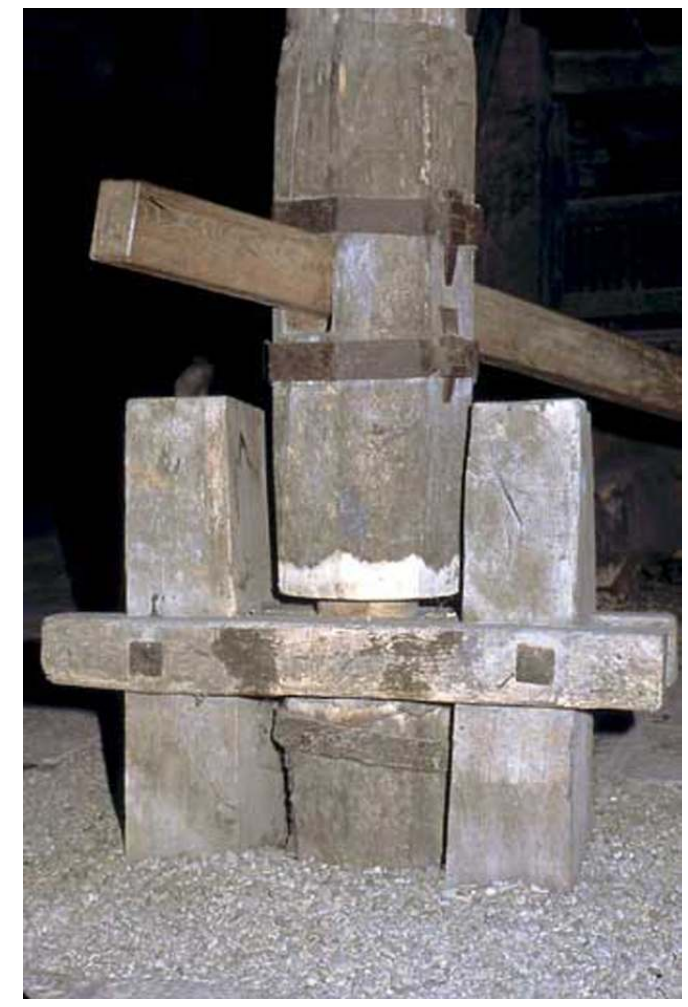

Pressoir à levier du Clos de Vougeot. Les taissons, la lanterne et l'étiquet, détail Phot. Inv. M. Thierry (c) Inventaire général, ADAGP, 2003 
Figure 7

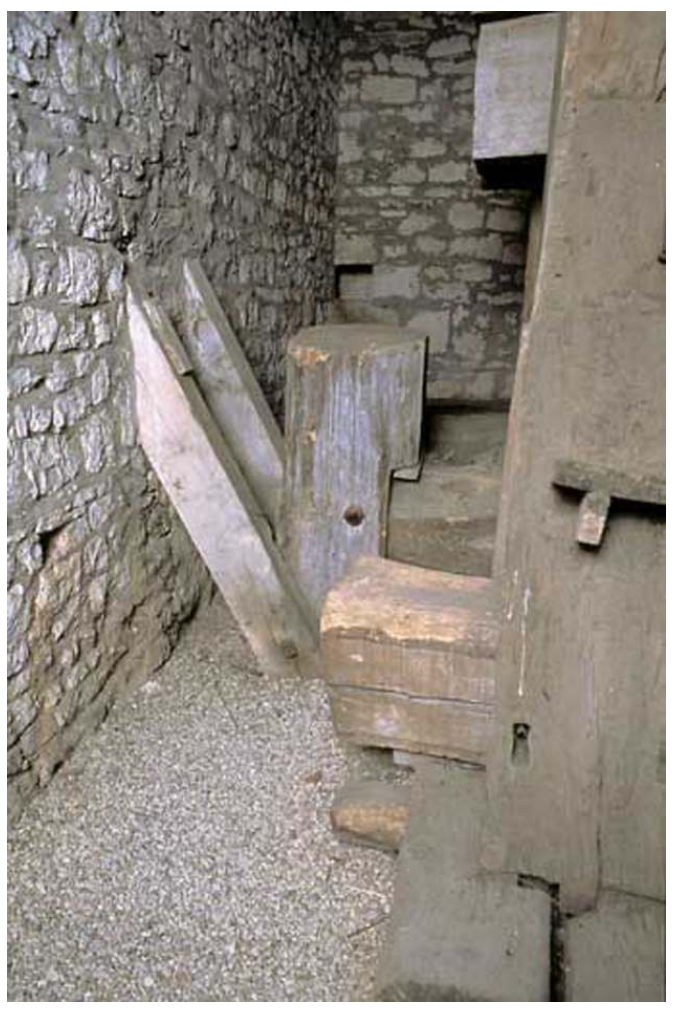

Pressoir à levier du Clos de Vougeot. Détail de l'ancrage de l'arrière du bâti Phot. Inv. M. Thierry @ Inventaire général, ADAGP, 2003 
Figure 8

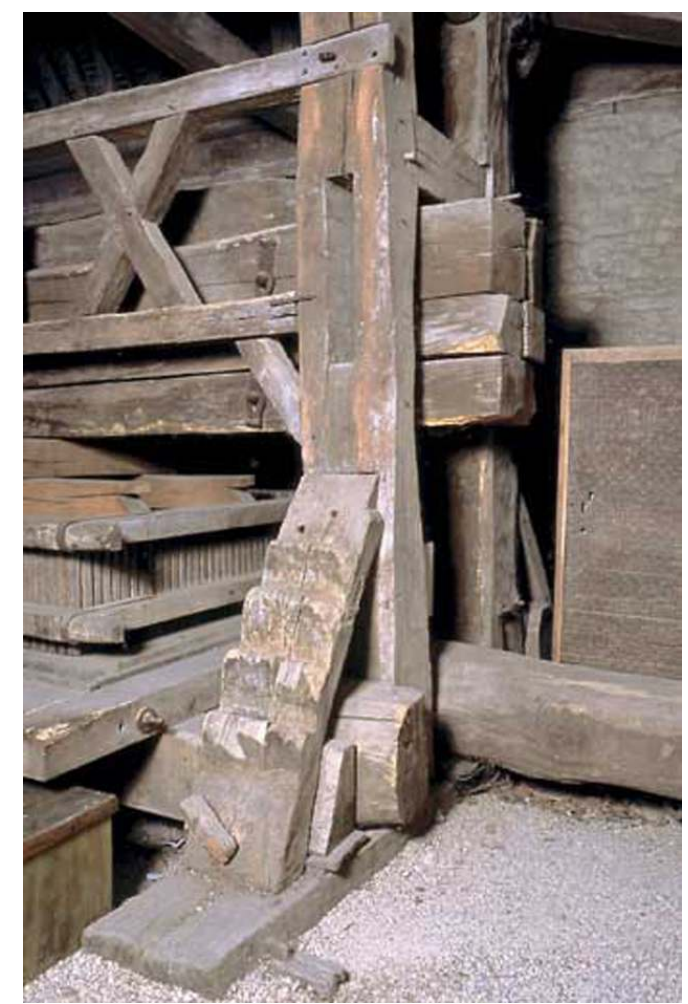

Pressoir à levier du Clos de Vougeot. Détail d'une jambe de force découpée en escalier Phot. Inv. M. Thierry @ Inventaire général, ADAGP, 2003

$\mathrm{Au}$ Clos de Vougeot, ainsi que sur d'autres pressoirs, comme sur celui d'Ozenay, pour faciliter l'accès à la maie (fig. $\mathbf{n}^{\circ} \mathbf{8}$ ), les jambes de force qui épaulent les ([jumelles]: *Jumelles*) du bâti sont découpées en escalier.

17 Avec les quatre pressoirs du Clos de Vougeot, le pressoir du manoir de La Perrière, à Fixin (Côte-d'Or), est un des rares pressoirs à levier de ce type conservés en Bourgogne. Il est installé dans le cellier d'un ancien domaine viticole des moines de Cîteaux, domaine qui fit fonction, en outre, de maison de convalescence pour les moines. Acquis en 1142, le manoir fut pillé par les huguenots en 1596 puis vendu quelques années plus tard aux Bouhier. Ce bâtiment des XII et XIII ${ }^{e}$ siècles, remanié à la fin du XVI ${ }^{e}$ siècle, est implanté sur un étage de soubassement occupé par de vastes caves dont les deux vaisseaux de cinq travées sont couverts de voûtes d'arêtes. Le pressoir est situé dans un angle du cellier où il occupe les deux travées antérieures.

18 Nous ne savons pas à quelle époque il y fut installé. Il est possible qu'il ne soit pas antérieur à la fin du XVI e siècle. Quoi qu'il en soit, sa structure massive, le traitement fruste des bois et la présence d'un étiquet, en font une des machines les plus archaïques de Côte-d'Or.

19 Au Clos de la Perrière comme au Clos de Vougeot, les taissons sont constitués par la fourche naturelle d'un orme ou d'un chêne. En revanche, le levier en chêne est ici monoxyle, sa section atteignant toutefois des dimensions respectables $(85 \mathrm{~cm}$ de largeur pour $55 \mathrm{~cm}$ de hauteur). La vis est tournée dans un tronc de sorbier, bois très serré résistant bien à la torsion. La perche, à épaulement, de 3,30 m de long, est en frêne dont le bois flexueux est préféré au chêne, ce dernier, plus " sec ", résistant moins à la rupture. L' 
([écrou] : $\left.{ }^{*} E c r o u *\right)$ de la vis est taillé dans un tronc d'orme noueux. Les autres parties de ces grands pressoirs bourguignons, bâti et levier, sont en chêne.

\section{Pressoir à levier, à vis actionnée par une roue à taquets}

Le système à étiquet présentait de nombreux inconvénients. La puissance de serrage était limitée à la résistance de la perche et, surtout, à celle de la lanterne. En outre, une perche ne pouvait être actionnée que par deux hommes. C'est pourquoi certains pressoirs à vis centrale sont actionnés par deux, voire trois étiquets.

Figure 9

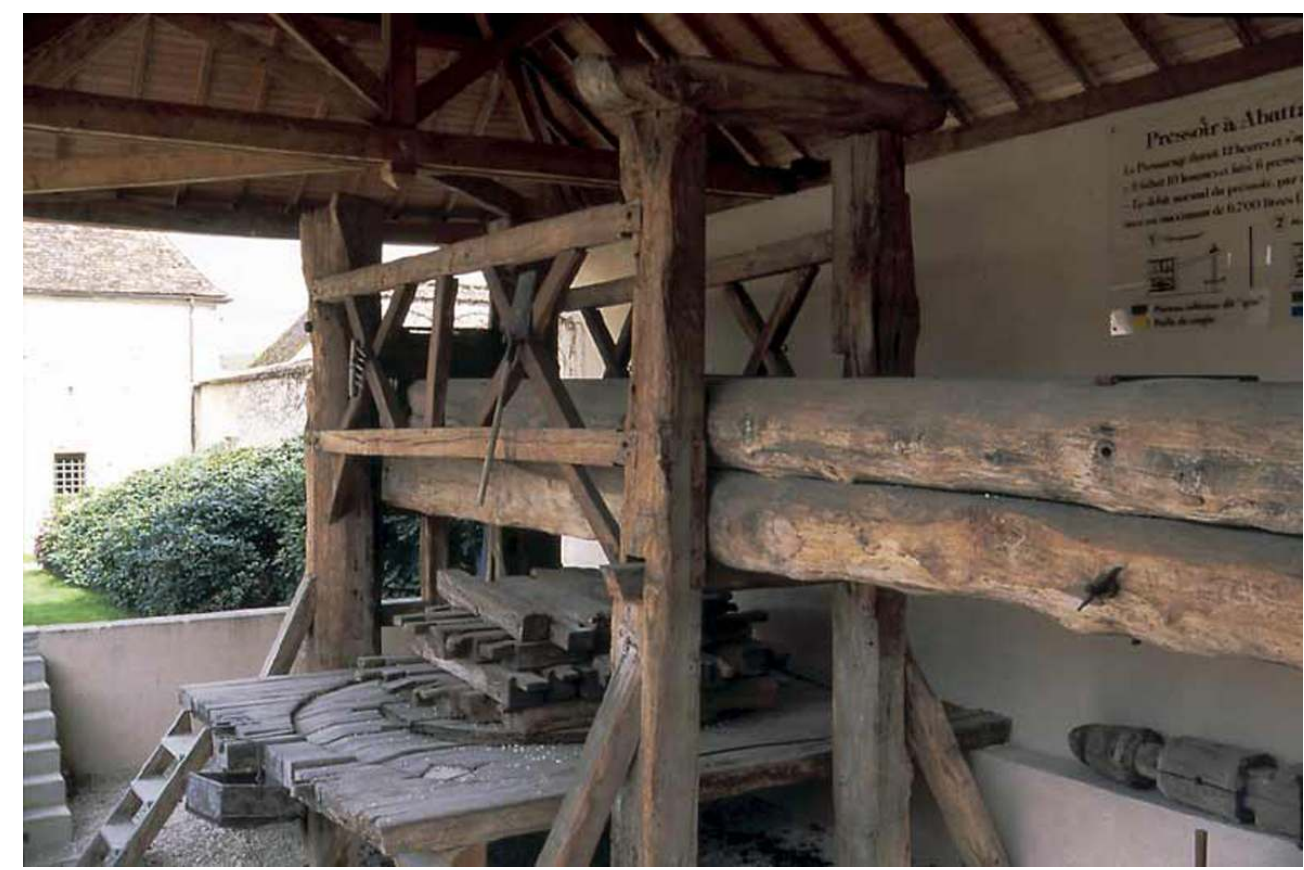

Pressoir à levier de l'ancienne obédiencerie, à Chablis, Yonne. Vue d'ensemble

Phot. Inv. B. Lauvergeon ( I Inventaire général, ADAGP, 2000 
Figure 10

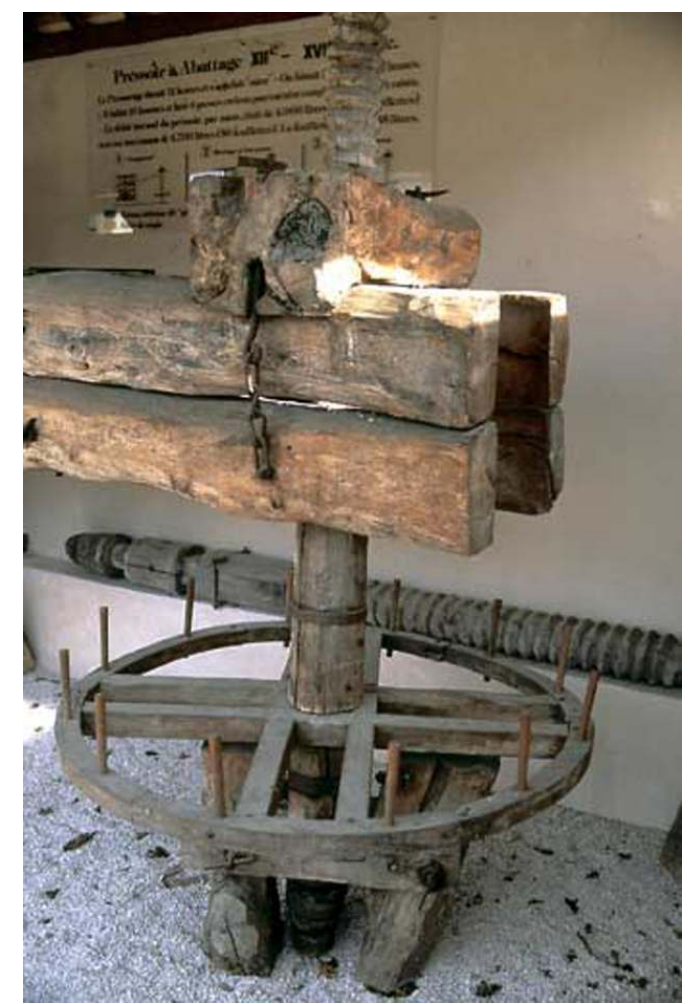

Pressoir à levier de l'ancienne obédiencerie, à Chablis, Yonne. La vis et la roue à taquets, détail Phot. Inv. B. Lauvergeon ( Inventaire général, ADAGP, 2000

21 Condamné par sa relative fragilité, ce système fut remplacé très tôt, sans doute dès la fin du Moyen Age, par la roue à chevilles, aussi appelée roue à taquets. Au lieu d'être actionnée par un ou deux forts bâtons qui traversent la lanterne, la vis est désormais serrée au moyen d'une roue dont les rayons enserrent le carré de la lanterne, la jante étant traversée par de longues chevilles. Les avantages de la roue à taquets sont multiples. Ces chevilles, dont le nombre est variable (de 12 à 16, parfois davantage sur les très grands pressoirs), autorisaient une importante main-d'œuvre pendant la pressée, plusieurs hommes pouvant actionner la roue simultanément. Il était en outre possible de s'aider d'une forte perche ou d'une barre de fer que l'on pouvait glisser entre les chevilles, ce qui augmentait encore la puissance de serrage. (fig. $\mathbf{n}^{\circ} \mathbf{1 0}$ ) Nous verrons d'ailleurs que ce perfectionnement, adopté sur les pressoirs à levier, fut apporté également aux pressoirs à vis centrale, pour lesquels les perches furent vite remplacées par une roue actionnée par un treuil mu par une grande roue à chevilles appelée roue à perroquet (fig. $\mathbf{n}^{\circ}$ 9).

C'est ce système à roue à chevilles qui fut adopté sur le pressoir du Petit Pontigny à Chablis (fig. $\mathbf{n}^{\circ} \mathbf{1 0}$ ), abrité sous une remise des bâtiments de l'ancienne obédiencerie, il est protégé par une inscription à l'inventaire supplémentaire depuis 1959, a été restauré et déplacé.

En revanche, le pressoir de Metz-le-Comte, au hameau de Champagne, plus tardif et de dimensions moins importantes (fig. $\mathbf{n}^{\circ} \mathbf{1 1}$ ), ne semble pas avoir subi de dommages. Il est toujours remisé dans l'enclos d'un ancien domaine de maître vigneron construit au XVII ${ }^{\mathrm{e}}$ siècle. Les dimensions de ce pressoir domestique n'ont évidemment rien de commun avec 
celles des grands pressoirs des châteaux et des abbayes. (fig. $\mathbf{n}^{\circ} \mathbf{1 1}$ ) A Metz-le-Comte, le levier de 7,30 m de longueur est constitué d'un seul tronc de chêne qu'alourdit un madrier posé sur l'extrados et le bâti n'est renforcé en partie haute que par quatre frêles pièces longitudinales dépourvues de tout contreventement. La surface de la maie n'excède pas $9 \mathrm{~m}^{2}$. Témoin du lointain passé viticole de ce site des Vaux d'Yonne, où la vigne ne subsiste plus que sur quelques rares parcelles de la côte de Cuzy, c'est le seul pressoir à levier du village, et l'un des derniers exemplaires de ces pressoirs domestiques qui équipèrent les domaines viticoles (un pressoir à vis centrale, plus tardif, daté de 1795, est conservé sur le même site).

Figure 11

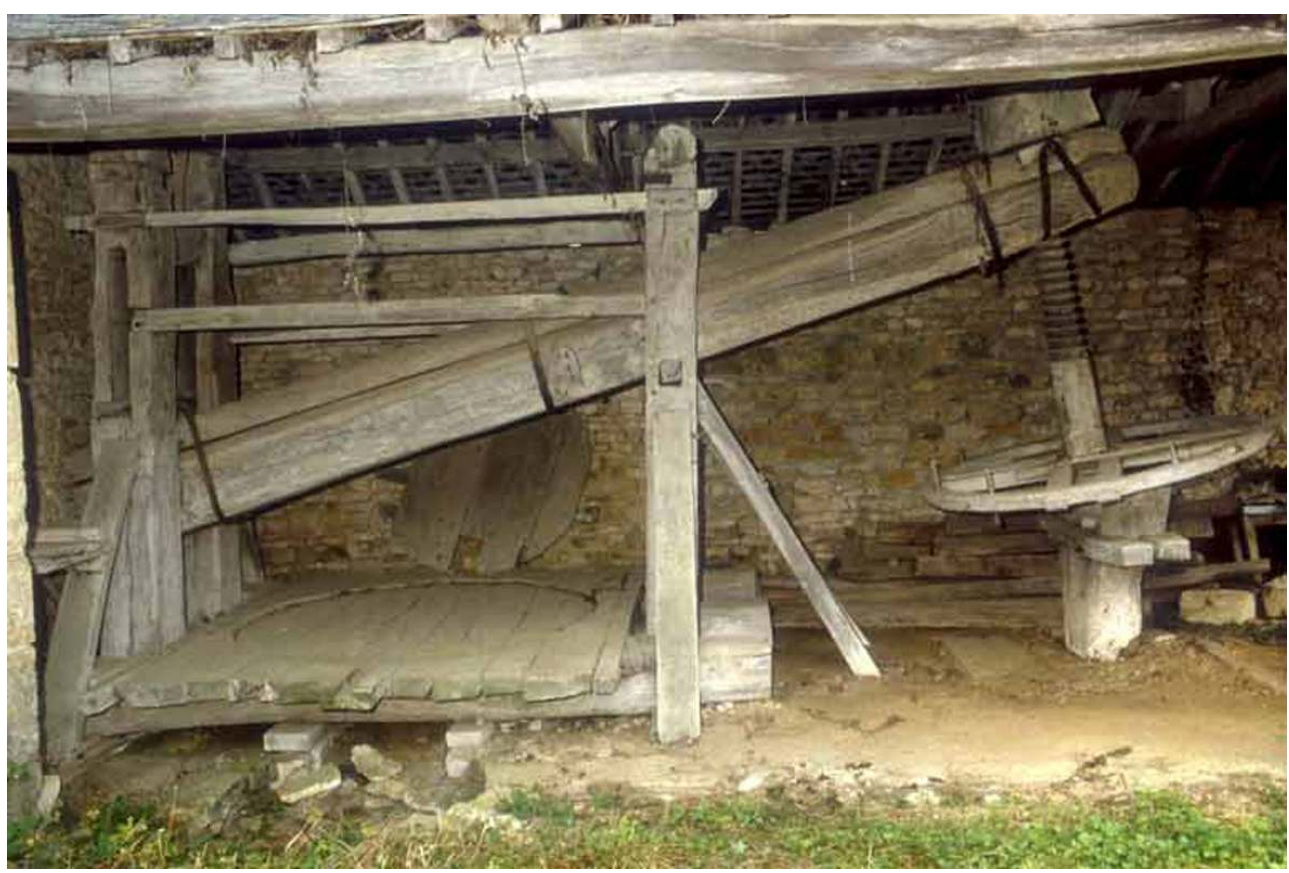

Pressoir à levier à Metz-le-Comte, au hameau de Champagne, Nièvre. Vue latérale

Phot. Inv. J.L. Duthu (@) Inventaire général, ADAGP, 1993

Ces roues à taquets furent adoptées sur presque toutes les variantes des pressoirs à levier qui furent utilisées jusqu'à l'apparition des pressoirs métalliques.

\section{Les pressoirs à levier à taissons lestés}

Le système à taissons enterrés n'a laissé que de rares témoignages en Bourgogne. Il semble, au regard des machines qui subsistent, qu'il fut abandonné dès la fin du XVII siècle, au profit d'autres systèmes plus fiables, tels que les taissons lestés, ou les taissons ancrés dans une fosse, le système à contrepoids étant, lui, exceptionnel.

Comme pour les pressoirs à levier à taissons enterrés, on retrouve les mêmes variantes sur les pressoirs à taissons lestés. Ces derniers présentent la particularité d'être pourvus, non pas de "taissons en pierre", mais de taissons en bois alourdis par des blocs de pierre de taille, ces lests permettant de faire l'économie d'un ancrage profond, ancrage parfois limité en profondeur par la nature même du sol de la cuverie, quand celle-ci, par exemple, occupe un rez-de-chaussée sur cave. C'est le cas de la cuverie du château de Vigne-le-Haut que nous évoquons dans ce chapitre. 


\section{A vis actionnée par une perche}

Nous connaissons peu de pressoirs à taissons lestés dont la vis est actionnée par un étiquet. Deux sont situés à Givry, en Saône-et-Loire. L'un, conservé au domaine Thénard à Givry (Saône-et-Loire), a été remonté à son emplacement actuel, mais une machine identique, et sans doute contemporaine, est encore visible non loin de là, au Cellier aux Moines. Cette dernière présente le double intérêt de ne pas avoir été déplacée et d'être datée de 1739 (date portée sur le lest et le levier).

\section{A vis actionnée par une roue à taquets}

C'est encore dans les Vaux d'Yonne, à Neuffontaines, dans la Nièvre, que nous avons découvert un pressoir à levier dont la vis, actionnée par une roue à taquets, est retenue par des taissons lestés.

Figure 12

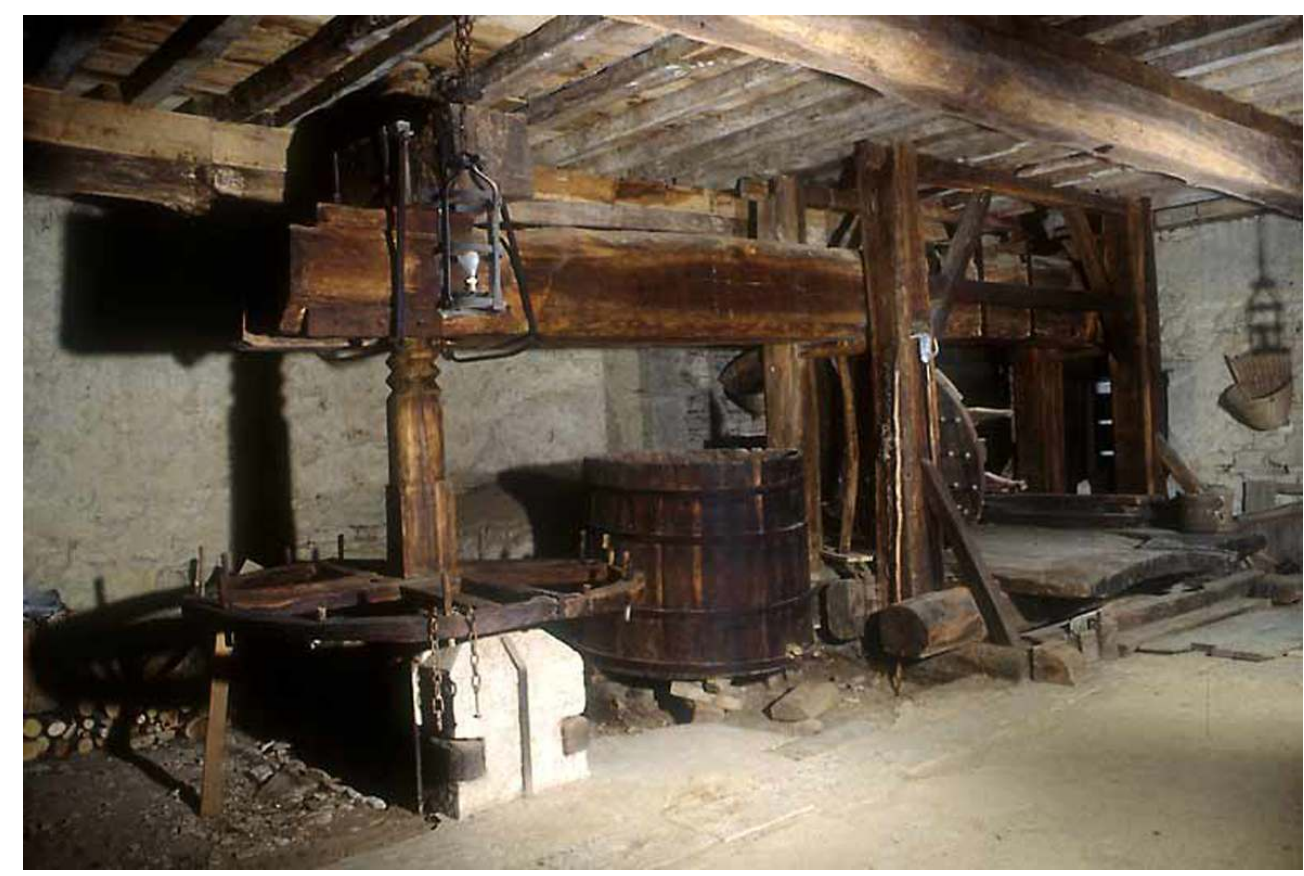

Pressoir à levier à taissons et contrepoids à Neuffontaines, au hameau de Vignes-Le-Haut, Nièvre. Vue d'ensemble

Phot. Inv. J.L. Duthu ( I) Inventaire général, ADAGP, 1994

Comme le pressoir du Cellier aux Moines, celui de Neuffontaines, conservé dans sa cuverie d'origine (fig. $\mathbf{n}^{\circ}$ 12) au château de Vignes-Le-Haut, porte, gravée sur le levier, la date 1792. Ses taissons sont lestés par de lourds blocs en pierre de taille calcaire. Les blocs jumelés sont réunis par des moises en chêne et ancrés dans le sol par des crampons en fer forgé. Un deuxième bloc de pierre de taille alourdit les colonnes postérieures du bâti qu'on appelle les jumelles, pour les distinguer des fausses jumelles situées, elles, en pendant, à l'avant du bâti. La présence de ces lourds lests de pierre s'explique en partie par la situation de la cuverie dont le sol repose sur l'extrados de la cave située au même aplomb. D’ailleurs, un orifice d'évacuation, ménagé sous la ([goulotte]: *Goulotte*), 
permettait de verser directement le jus qui s'écoulait de la maie dans une cuve située en dessous dans la cave.

La longueur du levier monoxyle de cet ancien pressoir seigneurial est de $8 \mathrm{~m}$ et la surface de la maie dépasse $12 \mathrm{~m}^{2}$. Bien que de dimensions supérieures au proche pressoir de Champagne, celui de Vignes-Le-Haut a lui aussi un levier monoxyle, énorme tronc de chêne renforcé au droit de la maie par des cerclages en fer forgé. Pas de contreventement non plus sur ce grand pressoir dont les pièces longitudinales du bâti sont simplement épaulées par des aisseliers.

Comment expliquer la présence de ces grands pressoirs sur des sites qui ne furent jamais des pays de monoculture de la vigne, même si l'implantation, la toponymie (Vignes-LeHaut, Vignes-Le-Bas) comme la typologie des maisons de ce hameau ne laissent aucun doute sur la nature des cultures qui, jusqu'à jusqu'à la crise du phylloxéra qui décima le vignoble des Vaux d'Yonne à la fin du XIX ${ }^{e}$ siècle, couvraient encore les coteaux les mieux exposés de cet écart de Neuffontaines? La carte du département de la Nièvre, dressée en 1878 par le Service vicinal, sous la direction du Ministère de l'Intérieur, montre que les vignes étaient présentes sur la quasi-totalité des communes du canton de Tannay.

Toutefois, la majorité de ces exploitations vouées à la polyculture et à l'élevage ne possédaient souvent que quelques arpents de vigne. Un pressoir à perche suffisait quand la récolte n'était pas pressée au pressoir communautaire. Seuls les châteaux et les domaines viticoles voués à la monoculture de la vigne, comme les grands domaines de la Côte viticole, pouvaient acquérir et entretenir un pressoir à levier. Leur importance, du reste, était proportionnelle à celle du domaine. (Rappelons que la surface de la maie du pressoir du domaine de Champagne n'atteint pas $9 \mathrm{~m}^{2}$ alors que la maie du plus grand pressoir du château du Clos de Vougeot dépasse $16 \mathrm{~m}^{2}$ ).

\section{Les pressoirs à levier à taissons ancrés dans une fosse}

Qu'ils fussent enterrés ou lestés, les taissons étaient sujets à la pourriture, comme toutes les pièces inférieures du pressoir, pieds des jumelles et patins du chantier, en particulier. Toutefois, ces derniers, très massifs, étaient moins exposés que ne l'étaient les taissons soumis à d'importantes forces d'arrachement. Nous l'avons vu, les taissons d'un des grands pressoirs du Clos de Vougeot durent être remplacés en raison de la pourriture qui avait gagné le pied et qui risquait de provoquer sa rupture.

34 Exception faite des contrepoids mobiles qui descendent dans un puits et qui constituent, en raison de leur conception, un type à part entière, seuls les taissons de deux grands pressoirs de l'Yonne présentent la très ingénieuse particularité d'être ancrés dans une fosse.

\section{Les pressoirs à levier à vis actionnée par une roue à taquets}

Ces deux pressoirs situés, l'un dans le Jovinien, à Champvallon, l'autre dans l'Auxerrois proche, à Coulanges-La-Vineuse (Yonne), appartiennent à la typologie des grands pressoirs à levier, dont la vis est actionnée par une roue à taquets, cette roue étant identique à celles déjà décrites. Nous ne connaissons pas de machine de ce type dont la vis était actionnée par un étiquet. 
L'originalité de ces deux grands pressoirs, dont les puissants leviers mesurent respectivement 9 et $10 \mathrm{~m}$ de long (ce qui les range aux côtés des plus grandes machines conservées en Bourgogne), réside dans le mode de fixation des taissons.

Figure 13

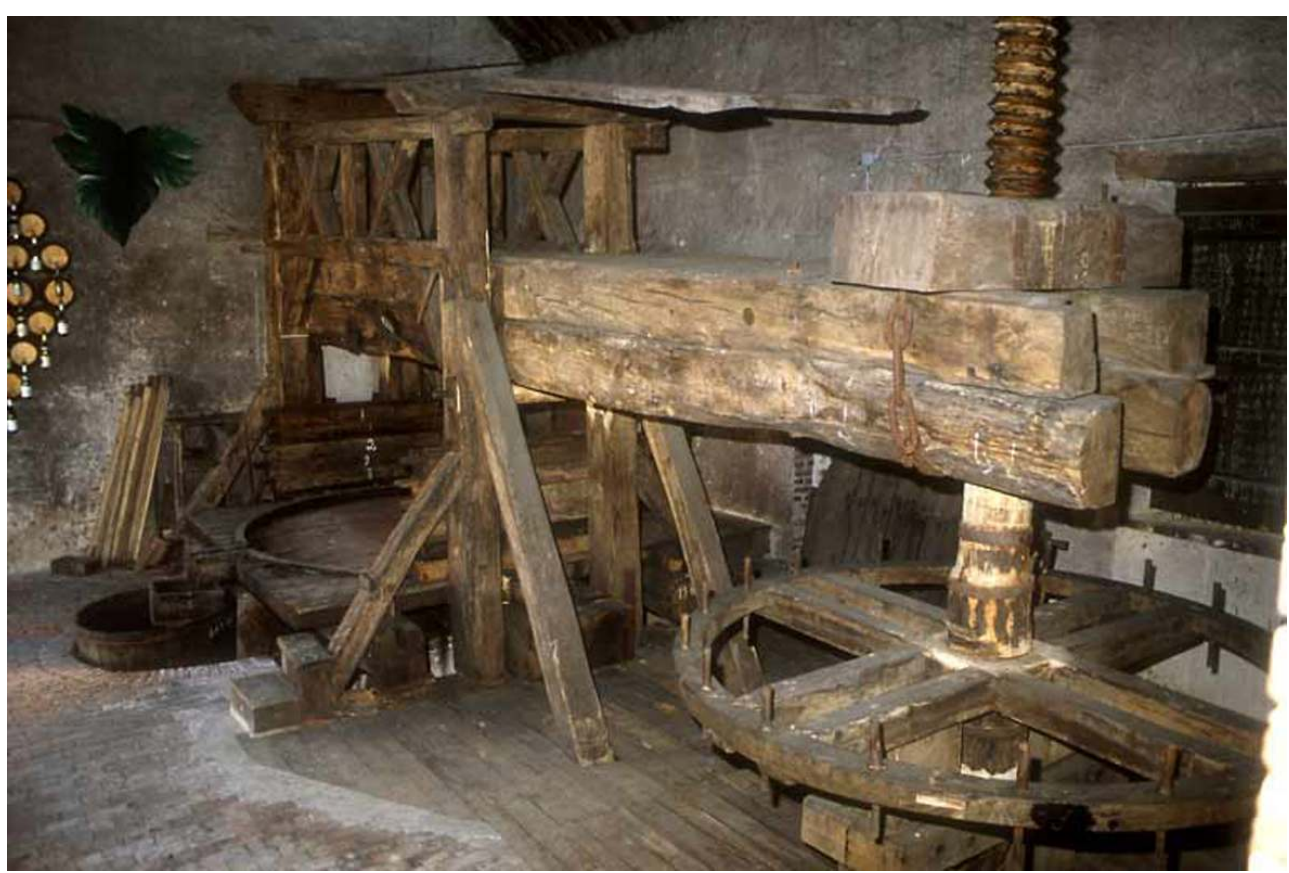

Pressoir à levier à taissons ancrés dans une fosse, à Champvallon, Yonne. Vue de trois-quarts

Phot. Inv. J.L. Duthu (C) Inventaire général, ADAGP, 1998

A Champvallon (fig. $\left.\mathbf{n}^{\circ} \mathbf{1 3}\right)$, les poutres jumelées des taissons plongent dans une fosse cylindrique maçonnée profonde de $7 \mathrm{~m}$ où elles sont bloquées par des madriers assemblés en croix de saint André. Cet ancien pressoir, qui a été déplacé et remonté à la fin du XVIII siècle dans la cuverie qu'il occupe toujours aujourd'hui, provient du château de Champvallon, qui fut la propriété de Jacques de Harlay, lequel aurait contraint Henri IV à lever le siège de Joigny en 1590 . Ses dimensions sont importantes : son levier, constitué de quatre troncs juxtaposés, mesure 9,50 m, et la surface de sa maie est proche de $15 \mathrm{~m}^{2}$. Quant à la grande roue à taquets, la plus grande qu'il nous ait été donné d'étudier, elle ne mesure pas moins de 2,70 $\mathrm{m}$ de diamètre.

Cette machine est remise en service, chaque année, le premier dimanche d'octobre, pour une pressée festive au cours de laquelle se retrouvent confréries vineuses et vignerons locaux. 


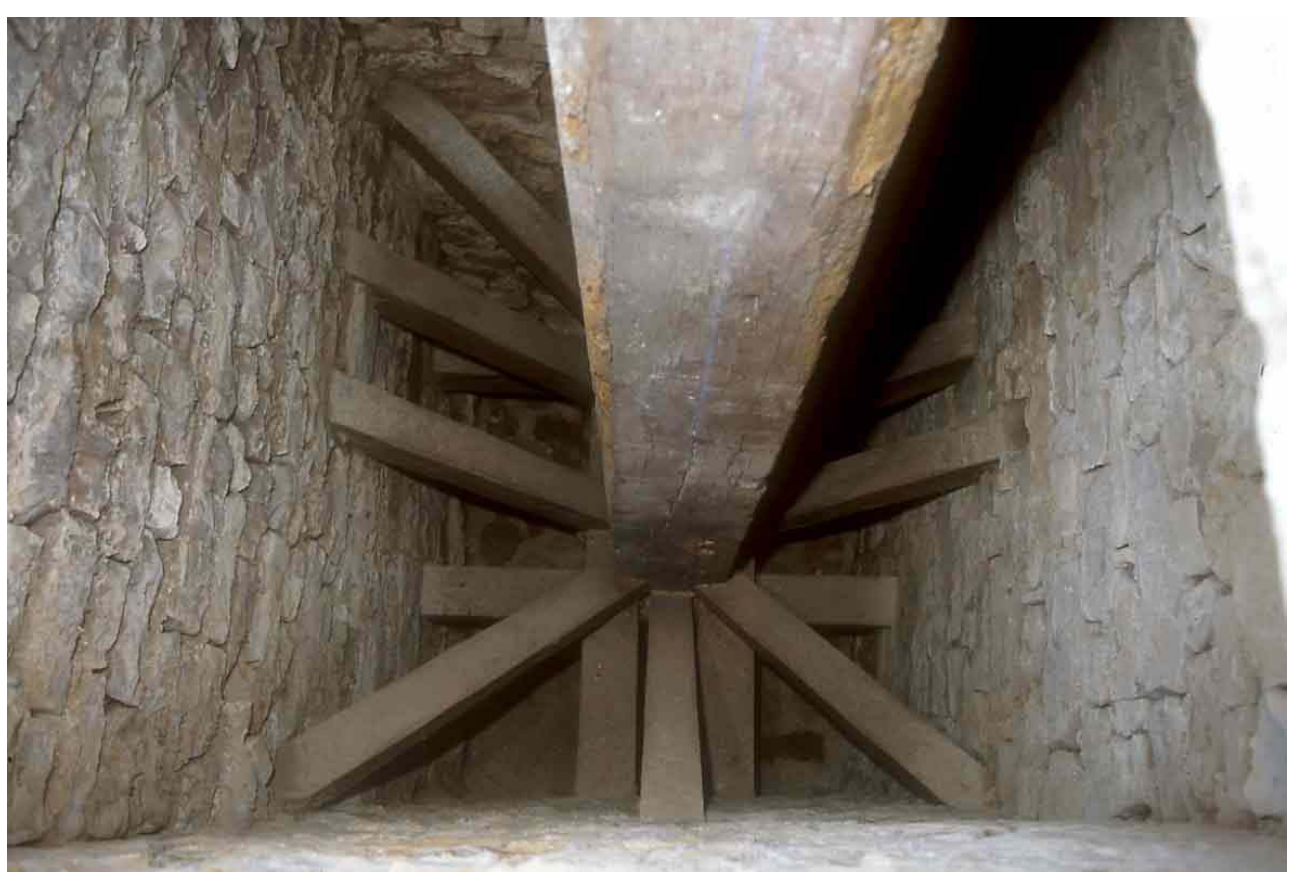

Pressoir à levier à taissons ancrés dans une fosse, à Coulanges-La-Vineuse, Yonne. Détail de la fosse Phot. Inv. J.L. Duthu @ Inventaire général, ADAGP, 1998

A Coulanges-La-Vineuse, les taissons sont ancrés dans un puits carré, soigneusement appareillé (fig. $\mathbf{n}^{\circ} \mathbf{1 4}$ ), profond de $4,50 \mathrm{~m}$. (fig. $\mathrm{n}^{\circ} 14$ ) Leur unique poutre massive est retenue par des madriers disposés en arêtes de poisson. Ce pressoir, fabriqué avec des chênes de la proche forêt de Saint-Fargeau, porte la date de 1757. La longueur de son levier massif, constitué de quatre troncs de chêne grossièrement équarris, que ceinturent de puissants fers plats, est de $10 \mathrm{~m}$ et la surface de la maie, une des plus importantes de toutes celles que nous avons étudiées, atteint $15 \mathrm{~m}^{2}$. En outre, les fausses jumelles sont ici renforcées par des jambes de force jumelées. Autre particularité: la cuve destinée à recueillir le jus est en pierre calcaire.

C'est le dernier exemplaire des nombreux pressoirs qui furent utilisés à Coulanges jusqu'au XIXe siècle (la ville en comptait encore une quinzaine à la fin du siècle). Propriété de la commune depuis 1983, il vient d'être inscrit à l'Inventaire Supplémentaire des Monuments Historiques.

41 Cette technique d'ancrage des taissons, que nous n'avons retrouvée sur aucun autre site, présente de nombreux avantages. Les puits étant ventilés, l'humidité y est moindre et le pied des taissons est, par conséquent, moins sujet à la pourriture. Par ailleurs, taissons et madriers, aisément accessibles, peuvent être inspectés et remplacés. Ce procédé ne semble pas avoir été très répandu. Quoi qu'il en soit, ces deux exemples intéressants témoignent d'un véritable savoir-faire et d'une réflexion aboutie.

\section{Les pressoirs à levier à contrepoids mobile}

De conception tout à fait singulière, les deux pressoirs jumelés conservés au Clos de Chenôve, dans l'ancienne cuverie des ducs de Bourgogne, comptent parmi les derniers témoins d'un type qui semble avoir été utilisé surtout dans le nord-est de la France, en 
lorraine, en Alsace et outre-Rhin, mais qui a pratiquement disparu, puisqu'on ne mentionne plus aujourd'hui pour la France, avec les deux appareils de Chenôve, que quelques grands pressoirs à raisin et à pommes, notamment en Moselle et en Meurthe-etMoselle où ils sont appelés " pressoirs à arbre ". Deux d'entre eux sont d'ailleurs protégés au titre des Monuments Historiques, d'autres sont aujourd'hui exposés dans des musées (Musée Historique Lorrain et Musée de Bar-le-Duc)ํ. Xavier Humbel (cf. bibliographie), quant à lui, signale deux machines démontées et déplacées, l'une provenant de l'abbaye de Mürbach, actuellement conservée dans le vignoble alsacien de Rouffach, l'autre transportée d'Epinal jusqu'au musée de Spire, en Allemagne.

Même si ces " pressoirs à arbre " lorrains et les deux pressoirs jumelés du Clos de Chenôve appartiennent à la même famille en raison de leur mode de fonctionnement (le contrepoids mobile), ils diffèrent par leur structure (bâti sans contreventement en Lorraine, troncs des leviers solidarisés par des étriers en bois appelés “ poupées ", comme sur le " pressoir à arbre" de Nouilly, dans la Moselle).

Des pressoirs sont attestés au Clos de Chenôve en 1238. L'activité du clos est prospère jusqu'au XVe siècle puis il passe dans le domaine royal en 1477 avant d'être loué à des particuliers. La cuverie est reconstruite vers 1400 puis remaniée à plusieurs reprises. Les pressoirs sont "reffaits à neuf" en 1401, à l'occasion de la reconstruction du bâtiment, puis restaurés en 1449; c'est ce qu'indiquent les analyses effectuées par le laboratoire de dendrochronologie de Besançon. Le bâtiment est ravagé par l'armée de Gallas ; il est dit ruiné en 1643.

Appelés "pressoirs à cage" dans La Nouvelle Maison Rustique, ils sont identiques aux pressoirs à levier, à étiquet, que nous venons de décrire, mais les taissons, au lieu d'être scellés dans le sol ou ancrés dans une fosse, sont lestés par une masse de pierre mobile, logée dans un puits cylindrique maçonné. Ces lests, d'un poids supérieur à 5 tonnes pour le plus important, sont constitués de plusieurs blocs en pierre de taille solidarisés par des moises en chêne.

Bien que certaines pièces du contreventement soient datées du milieu du XVe siècle, ces deux machines constituent, à l'évidence, un perfectionnement du système habituel des grands pressoirs dits "à taissons". Moins exposés à la pourriture que les taissons enterrés, ces contrepoids mobiles présentent en outre l'avantage d'éviter les pressions excessives et d'assurer une pressée régulière et continue sur les marcs. 
Figure 15

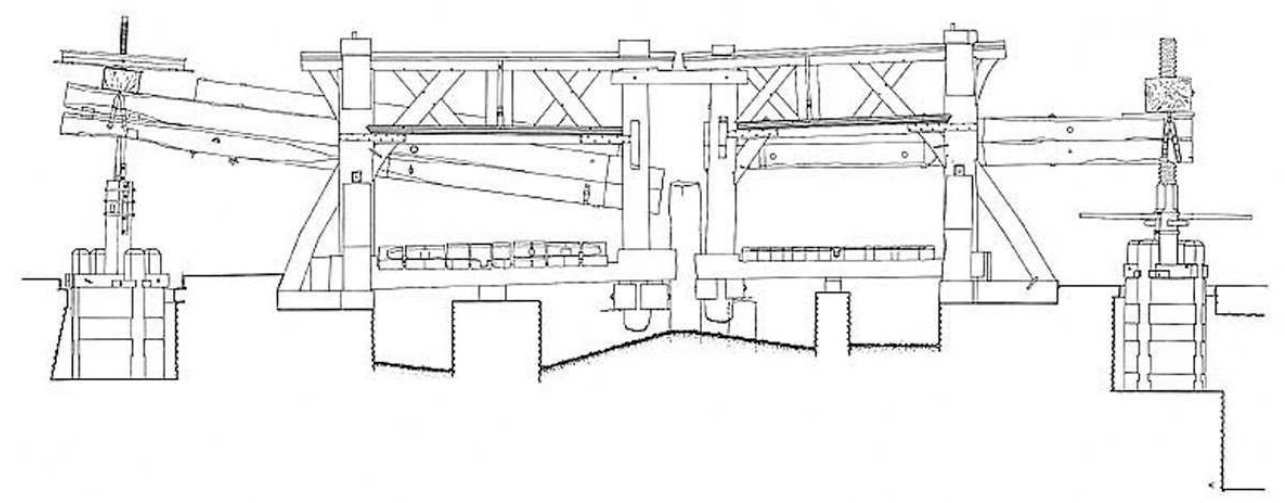

Pressoirs à levier, à contrepoids mobile, au Clos de Chenôve, Côte-d'Or. Elévation des deux pressoirs Relevé V. Lepais @ Inventaire général, ADAGP, 1999

47 Les taissons, la vis et le levier, mais aussi les jumelles, sujettes au déchaussement sur les appareils traditionnels, étaient ménagés par l'effet tampon du contrepoids, ce dernier se soulevant quand la pression devenait excessive. La masse du contrepoids participait ainsi à l'effort de presse tout en régulant la pressée (fig. $\left.\mathbf{n}^{\circ} \mathbf{1 5}\right)$.

Figure 16

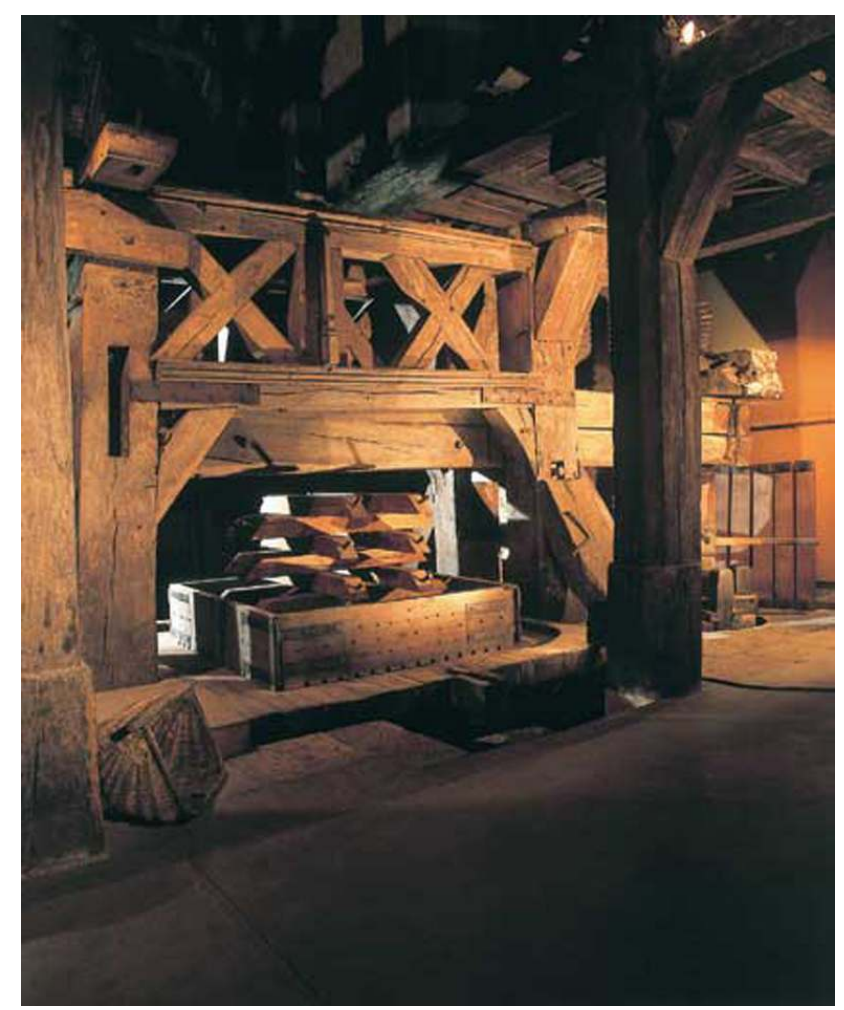

Pressoirs à levier, à contrepoids mobile, au Clos de Chenôve, Côte-d'Or. Le pressoir postérieur. Reconstitution d'une pressée

Phot. Inv. J.L. Duthu @ Inventaire général, ADAGP, 1999 
La structure de ces deux pressoirs est identique ; seules diffèrent leurs dimensions. Les leviers, constitués de quatre troncs de chêne équarris, mesurent respectivement $10 \mathrm{~m}$ pour le pressoir antérieur et $8 \mathrm{~m}$ pour l'autre pressoir; les surfaces des maies, proportionnées à la taille des machines, sont respectivement de $17 \mathrm{~m}^{2}$ et de $12 \mathrm{~m}^{2}$, le pressoir antérieur, le plus grand, étant par ses dimensions imposantes l'une des plus grandes machines de Bourgogne (fig. $\left.\mathbf{n}^{\circ} \mathbf{1 6}\right)$.

Figure 17

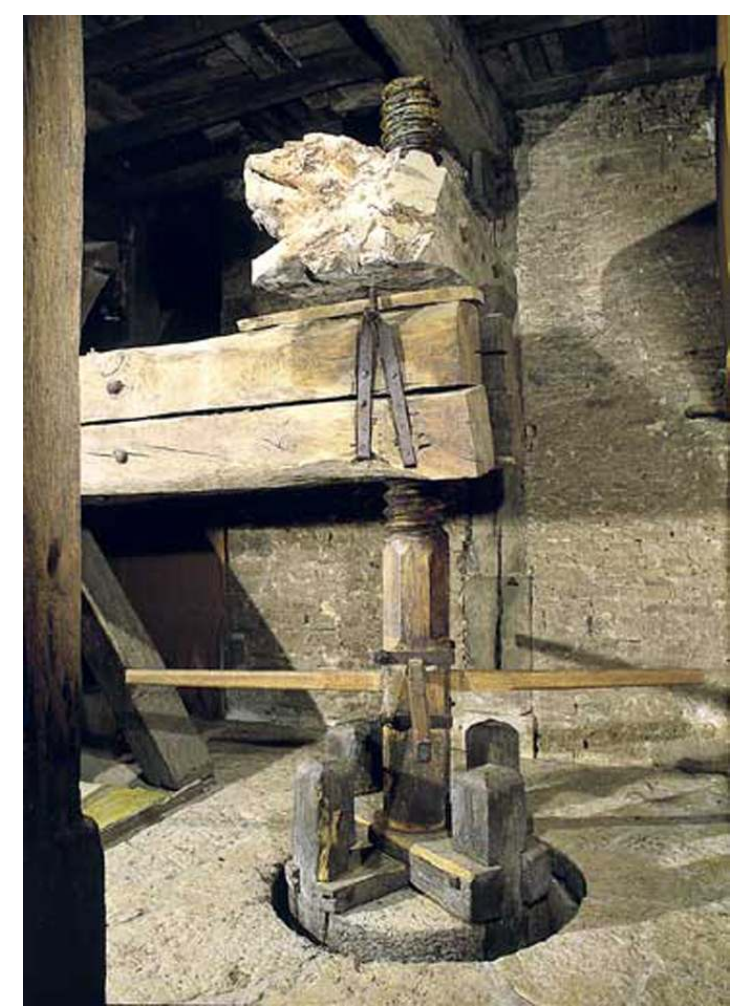

Pressoirs à levier, à contrepoids mobile, au Clos de Chenôve, Côte-d'Or. La vis et le contrepoids du pressoir postérieur, détail

Phot. Inv. J.L. Duthu @ Inventaire général, ADAGP, 1999

49 Ces pressoirs à contrepoids mobile étaient plus que de simples "écrasoirs", comme l'affirment certains auteurs, car les forces qu'ils développaient étaient aussi impressionnantes que le sont leurs dimensions. Après avoir été soulevées, les 5,5 tonnes du contrepoids (fig. $\mathbf{n}^{\circ}$ 17) du pressoir antérieur, qu'on appelle à Chenôve la "Margot", communiquaient en retombant une pression énorme qui s'exerçait sur les marcs par l'intermédiaire des cales et du ([manteau]: ${ }^{*}$ Manteau ${ }^{*}$ ). Cette pression théorique était ponctuellement de 21 tonnes pour le grand pressoir et les poussées que supportaient les aiguilles mises en blocage à l'arrière du levier étaient de l'ordre de 15 tonnes. Cela explique que ces aiguilles, bien qu'elles fussent en "bois de brin", se brisaient régulièrement. D'ailleurs on ne commençait jamais les vendanges sans pièces de rechange, étiquets, aiguilles, marres et même vis. 


\section{Les pressoirs à grand point}

50 des ducs étaient l'objet de réparations régulières quand ils n'étaient pas entièrement refaits. C'est ce que nous apprend la lecture des comptes des dépenses et recettes du clôsier du duc, à Chenôve. De 1366 et jusqu'au milieu du XVII ${ }^{\mathrm{e}}$ siècle, les interventions des charpentiers et ouvriers de bras se succèdent au clos. Matis (maie), arbre de treuil (levier), marres (cales), vis, pièces du bâti et même jumelles (les collonnes) doivent être régulièrement remplacés.

Aussi, pour limiter autant qu'il était possible ces incidents trop fréquents, un type de pressoir va se répandre dès le XVII ${ }^{e}$ siècle dans le sud de la Bourgogne, dans le Mâconnais, plus précisément, où d'ailleurs il restera confiné durant tout le XVIII ${ }^{\mathrm{e}}$ siècle et se généralisera. Seules quelques machines apparentées aux pressoirs à grand point seront adoptées en pays d'Othe pour la fabrication du cidre, la presse des pommes nécessitant des machines très puissantes. En raison de sa conception, le pressoir à grand point est en effet plus résistant aux fortes pressions que ne l'est le pressoir à levier. Ces machines, dont quelques exemplaires subsistent encore en Bourgogne du sud, s'apparentent aux pressoirs à levier, mais en diffèrent par la présence, en dessous de la maie, d'un arbre identique au levier et de même longueur, les deux troncs montés en parallèle travaillant à la façon d'une énorme tenaille. Pour augmenter la course du bras de levier, il était d'usage d'utiliser la courbure naturelle des troncs qui s'ouvrent à l'avant. Beaucoup plus massives que les pressoirs à levier et surtout plus courtes, le rendement de ces machines est inférieurs en raison, notamment, de la capacité plus réduite de leurs maies. Elles sont cependant très puissantes même si les leviers, généralement monoxyles, ont des sections bien inférieures à celles des leviers des pressoirs du Clos de Vougeot, par exemple. Contrairement à ce qui a été dit à propos des types précédents, les variantes de ces pressoirs à grand point sont exceptionnelles, leur structure ayant peu évolué. 


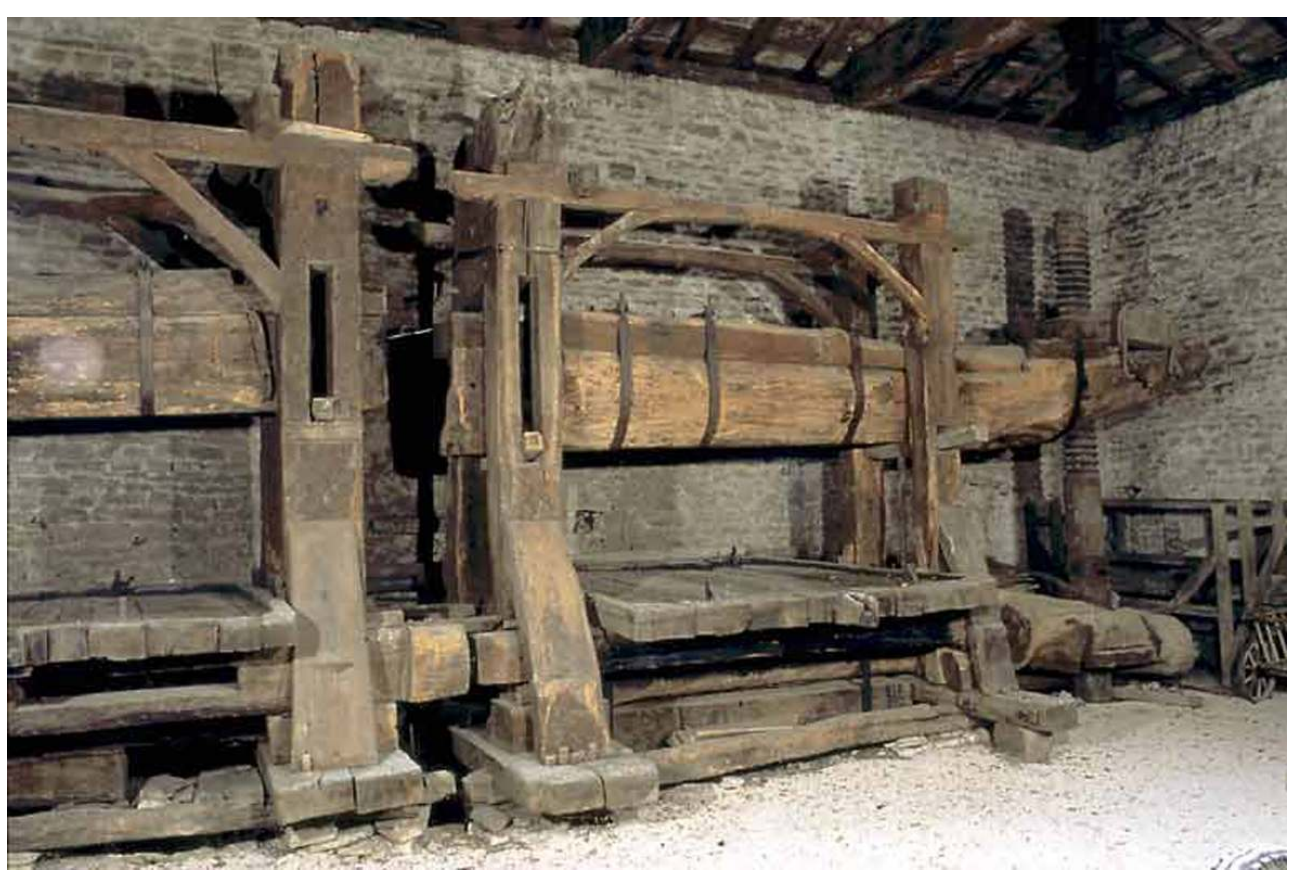

Pressoirs jumelés, à grand point, au château de Vinzelles, Saône-et-Loire. Vue d'ensemble de troisquarts

Phot. Inv. J.L. Duthu (C) Inventaire général, ADAGP, 2001

Deux pressoirs de ce type, derniers vestiges, d'après Xavier Humbel, d'une batterie de sept machines, ont été conservés dans le tinailler du château de Vinzelles (Saône-etLoire). Sur un des deux pressoirs on lit la date 1716 (fig. $\mathbf{n}^{\circ} \mathbf{1 8}$ ).

Les deux châteaux de Vinzelles, le vieux château et le château de Layé, sont implantés dans un site exceptionnel, à quelques kilomètres au sud-ouest de Mâcon. Le vieux château du XII ${ }^{e}$ siècle est situé en croissant au nord du site ; quant au château de Layé, qui datait du XIII ${ }^{e}$ siècle, il fut reconstruit au début du XVII ${ }^{e}$ siècle, puis profondément remanié vers 1850 après un violent incendie. Les deux châteaux sont séparés par une terrasse qu'occupe un vaste tinailler. C'est dans ce long bâtiment que sont remisés les deux grands pressoirs. 
Figure 19

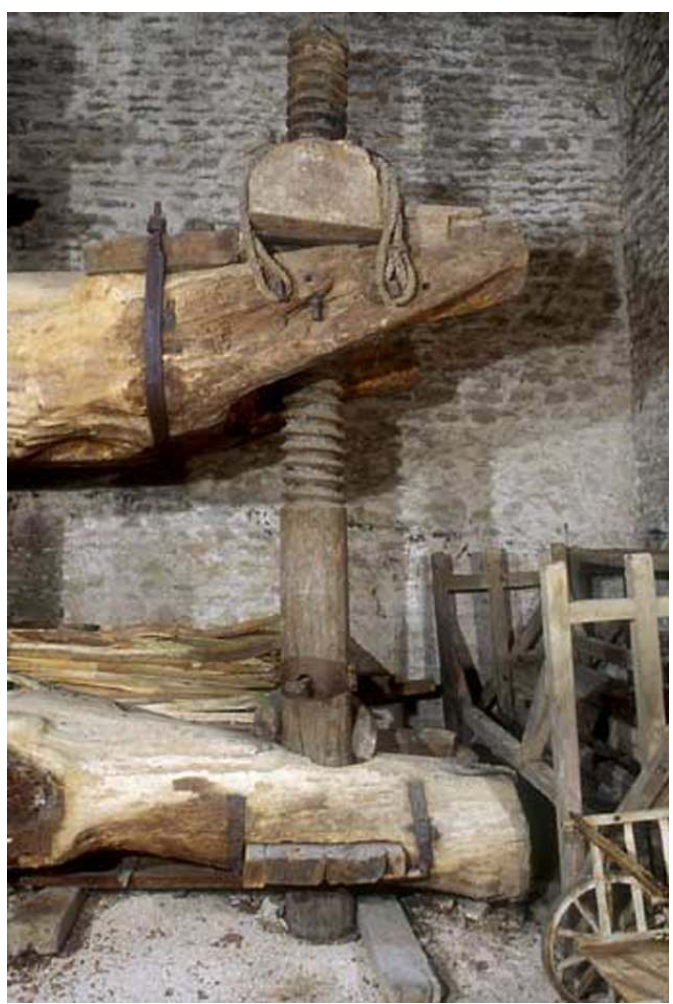

Pressoirs jumelés, à grand point, au château de Vinzelles, Saône-et-Loire. Détail de l'avant du pressoir postérieur

Phot. Inv. J.L. Duthu ( Inventaire général, ADAGP, 2001

Leurs leviers massifs, ont été renforcés par des madriers posés sur l'extrados et ceinturés par des fers plats, mais leur longueur n'excède pas 6,30 m Quant aux surfaces des maies, relativement réduites, de l'ordre de $6,50 \mathrm{~m}^{2}$, elles sont bien inférieures à celles des grands pressoirs à levier que nous venons d'évoquer. Autre particularité de ces pressoirs, la vis, dont la base est renforcée par un fer plat hélicoïdal, est actionnée par une forte perche, qu'on appelle localement la "gosanche". A la différence de l'étiquet, ce n'est pas la gosanche qui est engagée dans la mortaise de la lanterne, mais une barre de fer qui traverse sa fourche naturelle (fig. $\mathbf{n}^{\circ} \mathbf{1 9}$ ).

Les deux pressoirs qui subsistent dans le tinailler du château de Vinzelles sont jumelés dos à dos comme le sont les deux machines du Clos de Chenôve, cette disposition renforçant évidemment leur stabilité et leur résistance aux forces d'arrachement qui s'exercent à l'arrière pendant les pressées. 
Figure 20

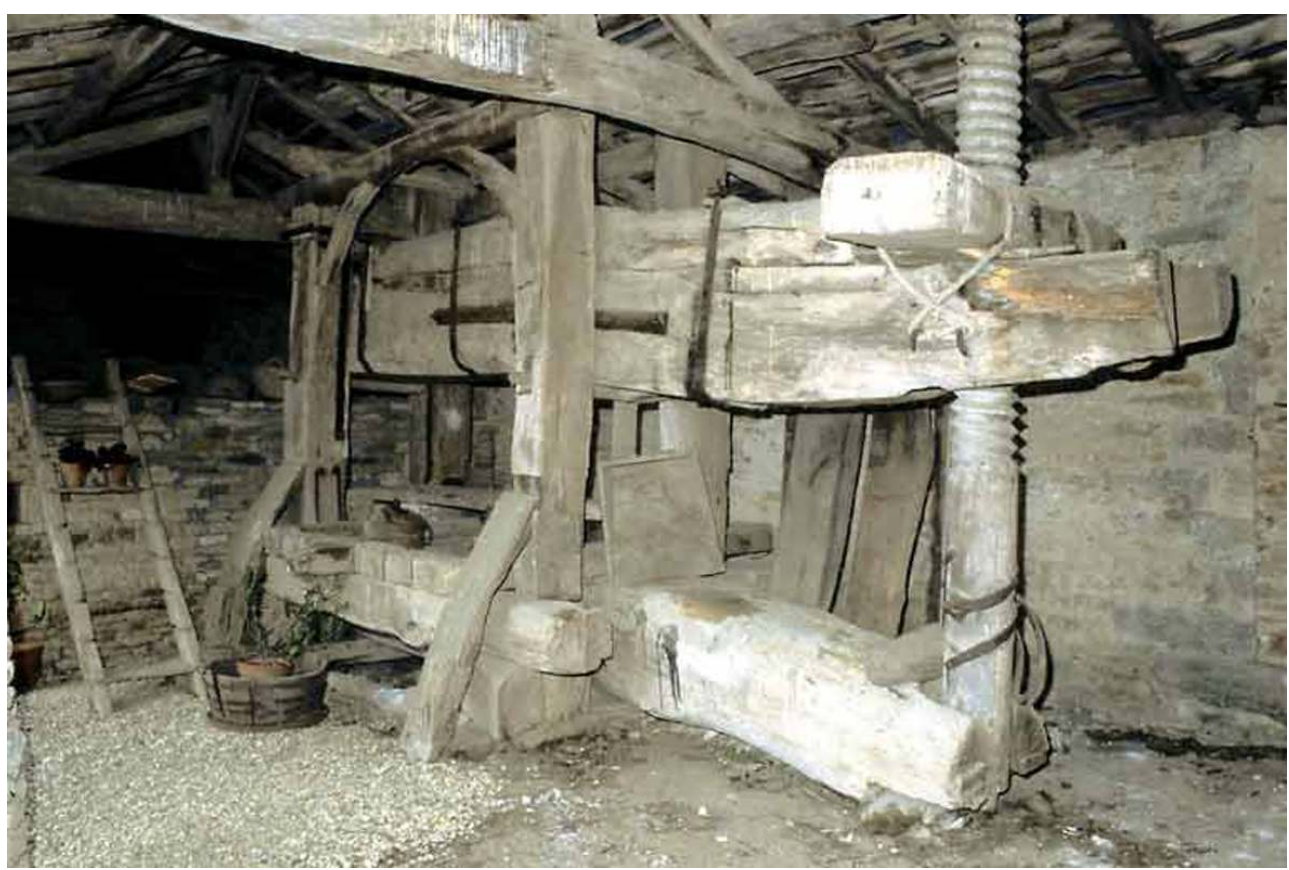

Pressoir à grand point du domaine du Vernay, à Mazille, Saône-et-Loire. Vue d'ensemble de troisquarts

Phot. Inv. J.L. Duthu ( Inventaire général, ADAGP, 2001

Le pressoir de Mazille, au domaine du Vernay (Saône-et-Loire), est représentatif des nombreux pressoirs à grand point qui furent utilisés dans les domaines viticoles du Mâconnais jusqu'à la fin du $19^{\mathrm{e}}$ siècle (fig. $\mathbf{n}^{\circ}$ 20).

57 Ce domaine fut construit en 1769 par les Teyras, famille ardéchoise qui possédait deux autres domaines dans la région. Avant d'être converti en exploitation agricole, le domaine du Vernay fut une maison de vigneron et de négociant en vin jusqu'à la fin du XIX ${ }^{e}$ siècle quand fut abandonné le vignoble de Mazille. Les bâtiments furent restaurés et agrandis tout au long du XIXe siècle. 
Figure 21

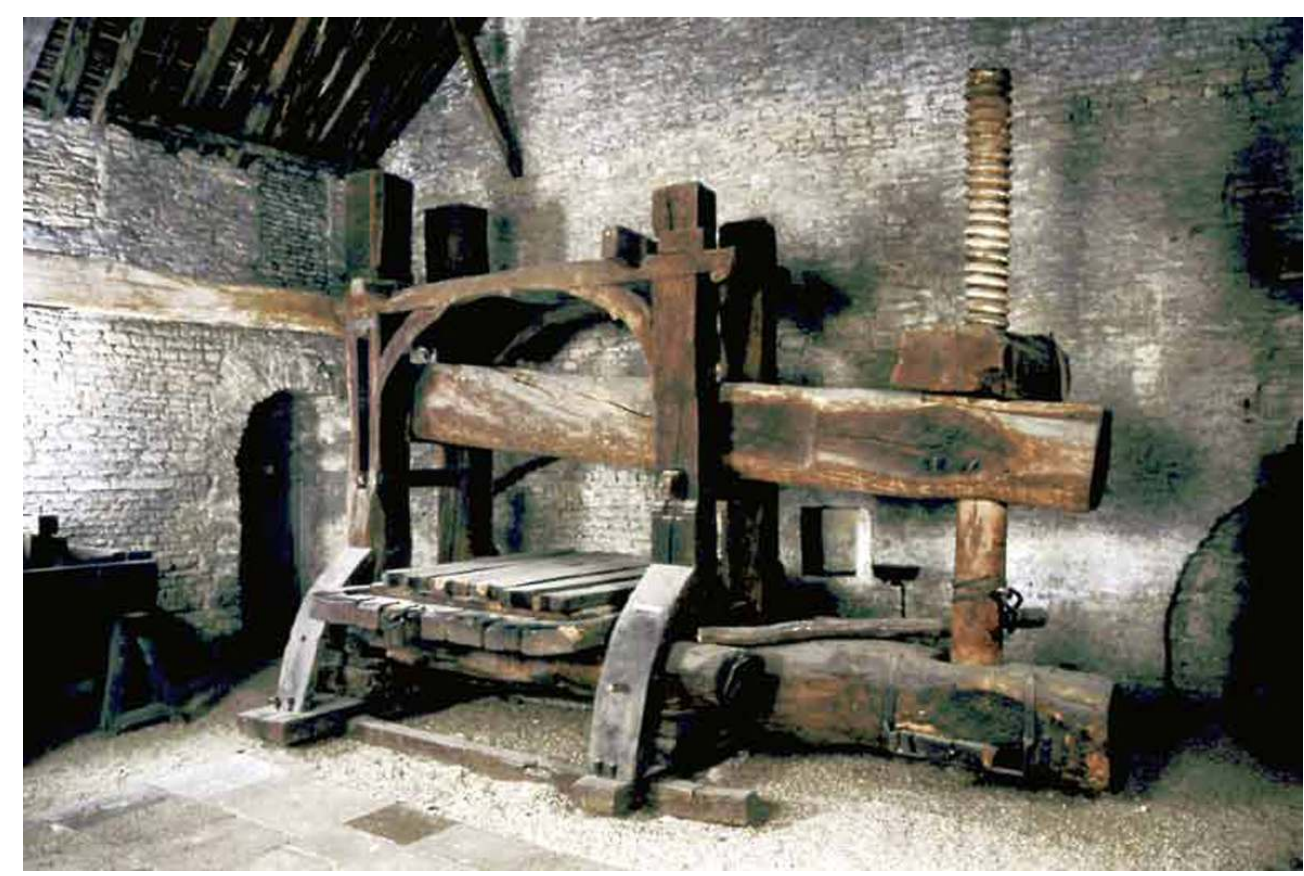

Pressoir à grand point d'Hurigny, Saône-et-Loire, conservé au Musée du Vin à Beaune. Vue d'ensemble Phot. Inv. M. Thierry @ Inventaire général, ADAGP, 2002

Le pressoir du Vernay présente les mêmes caractéristiques que ceux de Vinzelles et ses dimensions sont identiques; il est abrité sous une remise ouverte, à pile, caractéristique de cette région du Mâconnais. Son levier a, lui aussi, été surchargé et fortement ceinturé par quatre fers forgés. (fig. $\mathbf{n}^{\circ}$ 22) On s'explique mal la présence presque systématique de tels renforts, qui sont aussi des surcharges, sur des troncs dont la section est souvent considérable. Il est possible que ces surcharges ne soient pas seulement une garantie contre l'éclatement, mais aussi le moyen d'augmenter les rendements en alourdissant le levier. La gosanche est ici un simple bâton sinueux (fig. $\mathbf{n}^{\circ} \mathbf{2 1}$ ) que l'on glissait dans l'anneau forgé solidaire de la barre de fer qui traverse le pied de la vis. 
Figure 22

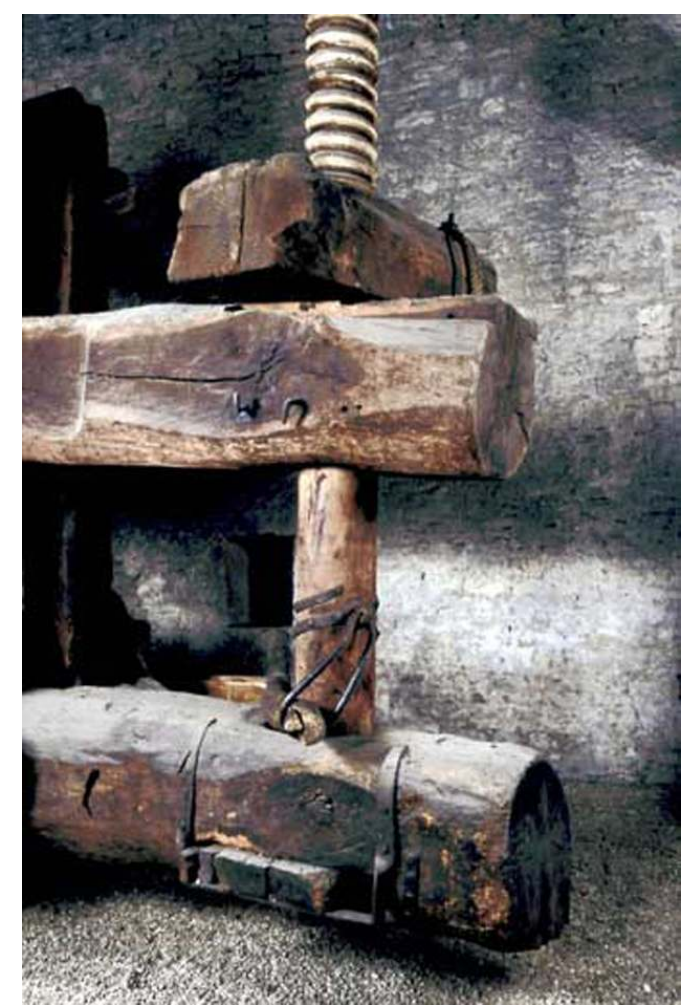

Pressoir à grand point d'Hurigny, Saône-et-Loire, conservé au Musée du Vin à Beaune. L'avant du pressoir, l'anneau et la perche, détail

Phot. Inv. M. Thierry @ Inventaire général, ADAGP, 2002

On retrouve ce même dispositif sur un des pressoirs à grand point du Musée du Vin à Beaune, provenant d'Hurigny, en Mâconnais (fig. $\mathbf{n}^{\circ}$ 22).

\section{Le pressoir du château d'Ozenay (Saône-et-Loire)}


Figure 23

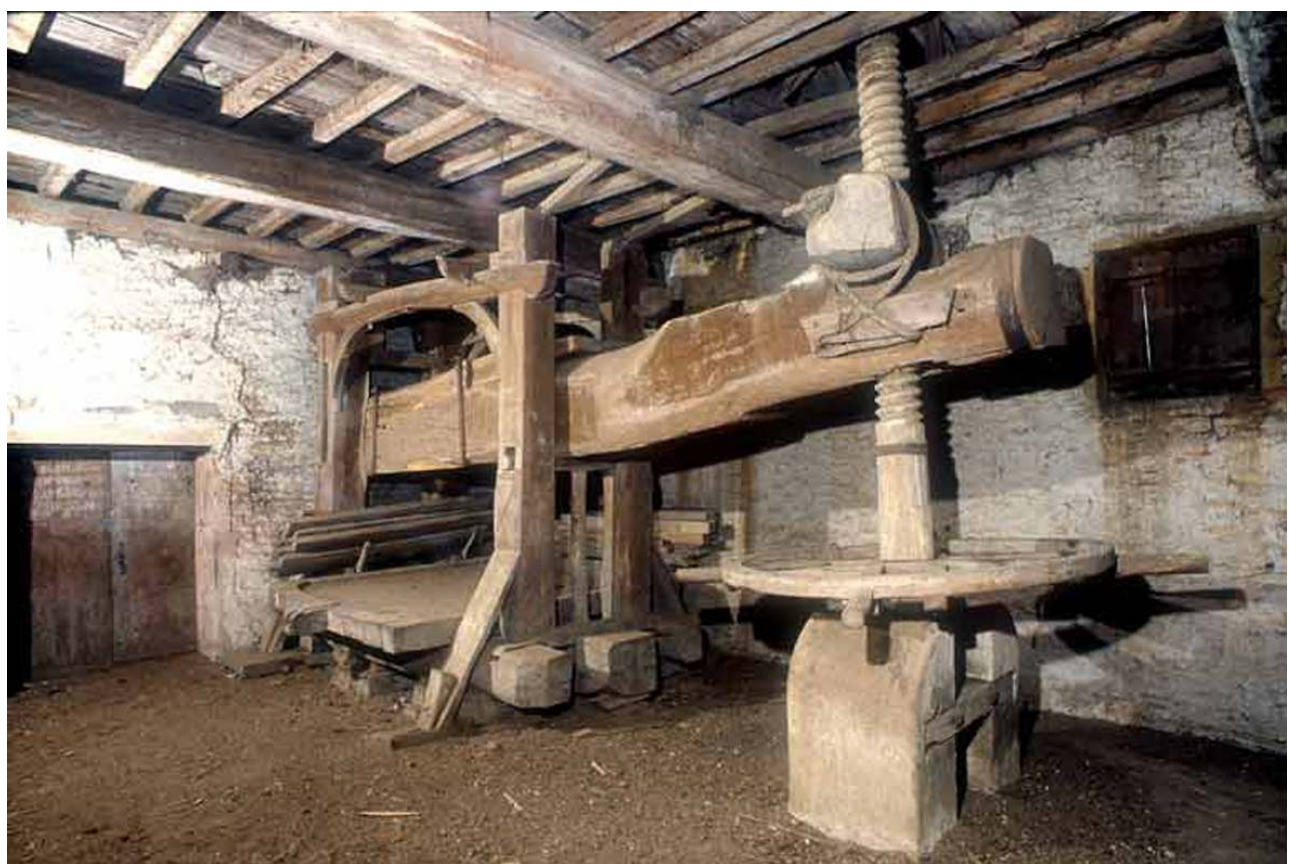

Pressoir à levier du château d'Ozenay, Saône-et-Loire. Vue d'ensemble

Phot. Inv. J.L. Duthu (c) Inventaire général, ADAGP, 2003

Le pressoir d'Ozenay (fig. $\mathrm{n}^{\circ} 23$ ), village viticole du Tournugeois, est d'un type singulier, sa structure étant un compromis entre celles des pressoirs à levier et des pressoirs à grand point.

Figure 24

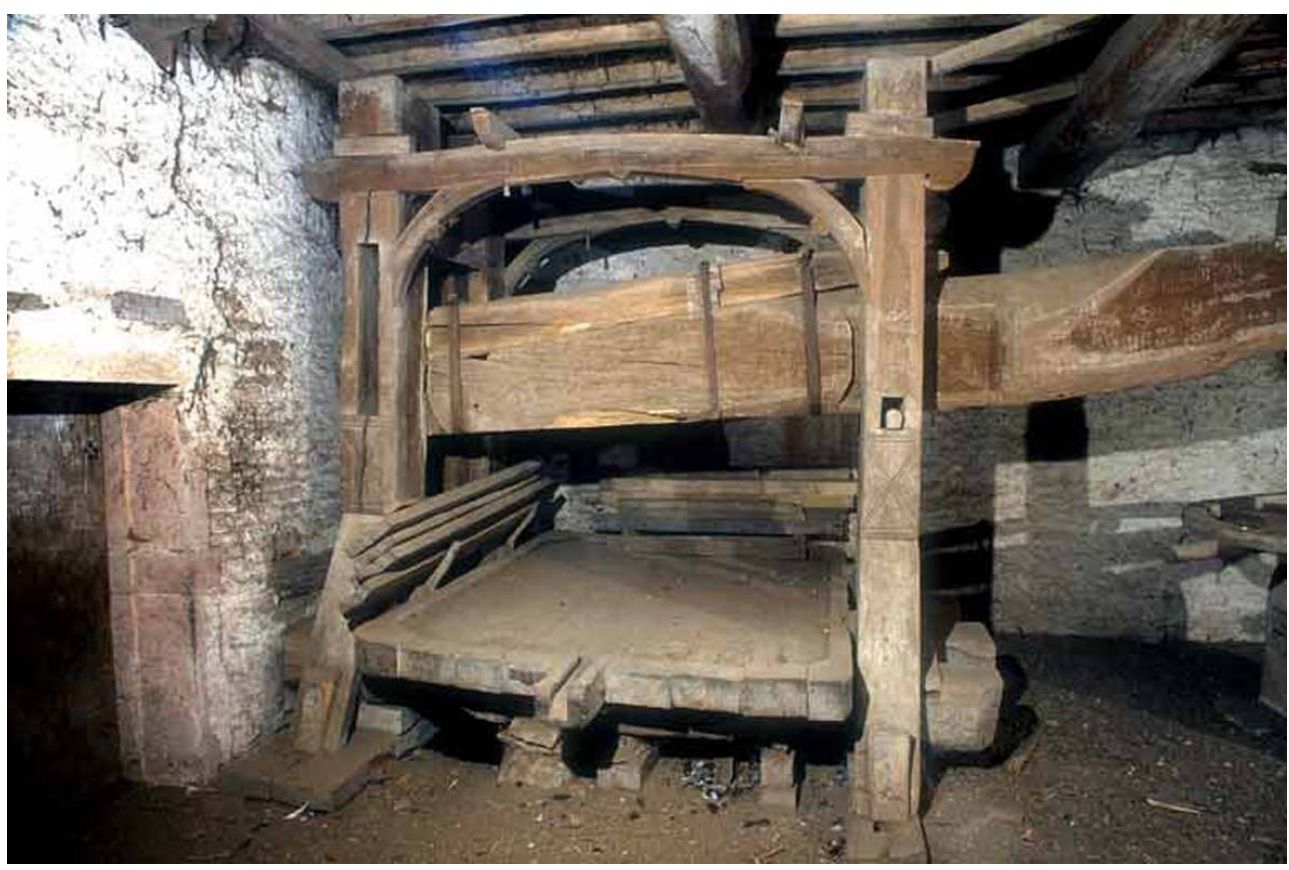

Pressoir à levier du château d'Ozenay, Saône-et-Loire. Détail du bâti Phot. Inv. J.L. Duthu ( Inventaire général, ADAGP, 2003 
61 Il est le dernier d'une batterie de plusieurs machines qui étaient abritées dans le vaste tinailler du château. Comme le pressoir du village voisin de Martailly-lès-Brancion, celui d'Ozenay appartient par son mode de fonctionnement à la typologie des pressoirs à levier, mais la structure de son bâti est identique à celle des pressoirs à grand point : les jumelles comme les fausses jumelles sont épaulées par de frêles jambes de force et elles ne sont assemblées en partie haute que par deux pièces longitudinales qu'épaulent de courts aisseliers à découpe cintrée et à décors de pointes de diamant, aisseliers caractéristiques des superstructures des pressoirs à grand point du Mâconnais. Pas de contreventement non plus, pas de potelet ni de croix de saint André, mais une structure visiblement empruntée à celle des pressoirs à grand point (fig. $n^{\circ} 24$ ) traditionnellement utilisés dans la région.

Figure 25

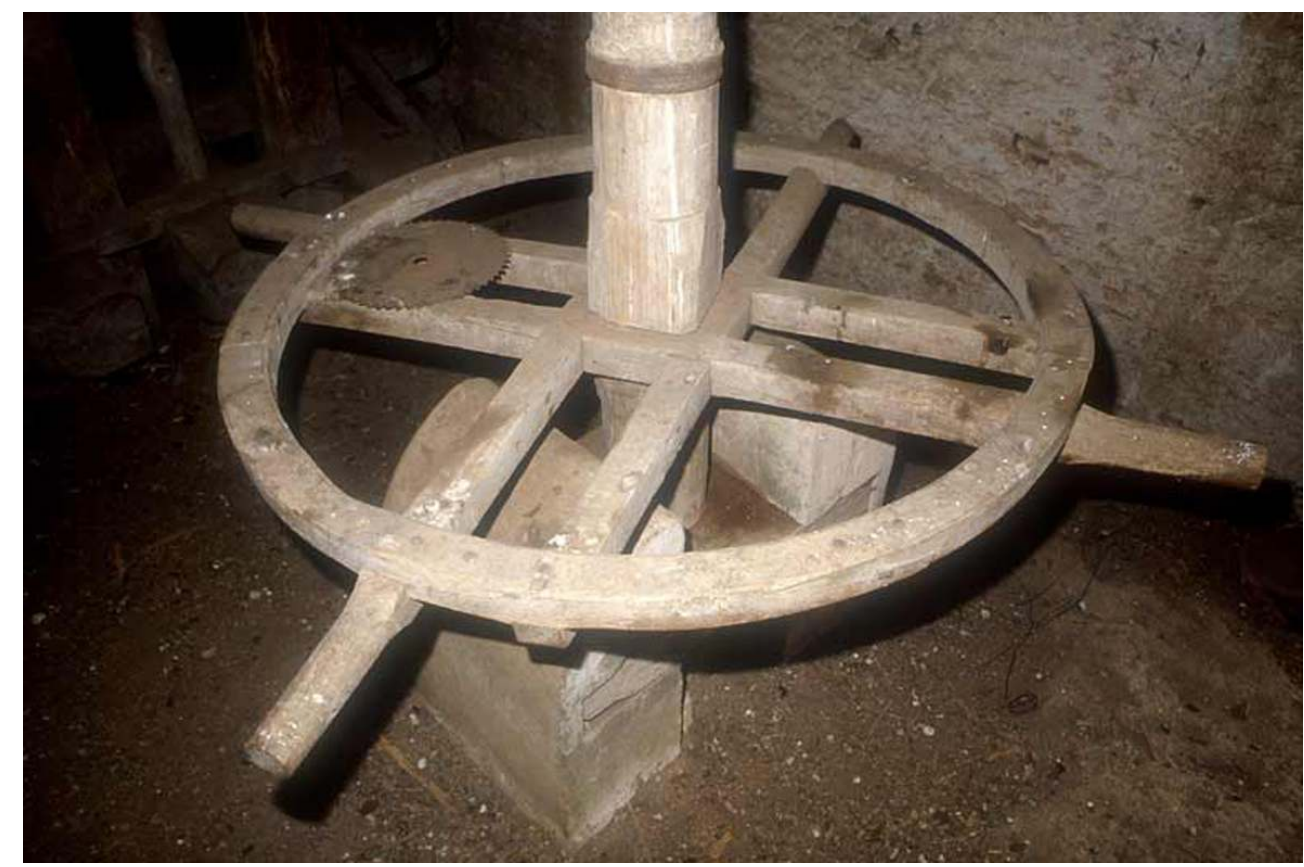

Pressoir à levier du château d'Ozenay, Saône-et-Loire. Détail de la roue à poignées

Phot. Inv. J.L. Duthu ( Inventaire général, ADAGP, 2003 
Figure 26

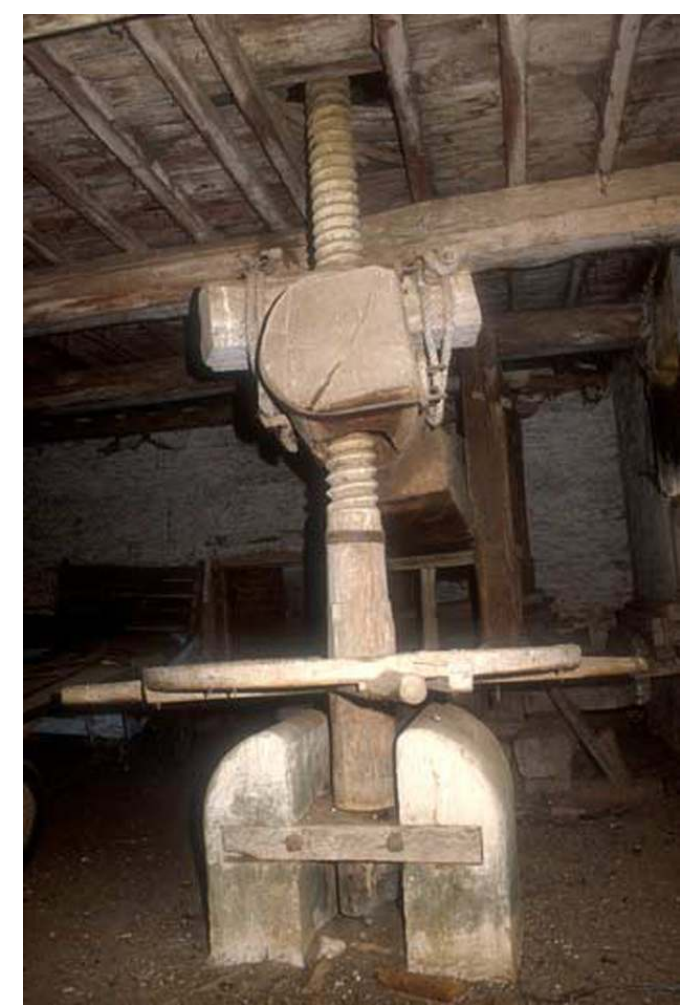

Pressoir à levier du château d'Ozenay, Saône-et-Loire. L'avant du pressoir. Vue frontale Phot. Inv. J.L. Duthu @ Inventaire général, ADAGP, 2003

Autre originalité à Ozenay : la roue, solidaire de la vis, est actionnée par quatre rayons dépassants faisant fonction de poignées (fig. $n^{\circ} 25$ ), la vis étant habituellement tirée par une roue hérissée de chevilles, ou taquets.

63 La machine est en outre, ornée de filets et de denticules gravés au ciseau, sur les jumelles, les fausses jumelles et le levier, et d'un feston sculpté à la base de la vis. D'une typologie singulière et d'une facture exceptionnelle, elle a fait récemment l'objet d'une demande de protection au titre des Monuments Historiques (fig. $n^{\circ} 26$ ).

$64 \mathrm{Au}$ village voisin de Martailly-lès-Brancion, un pressoir de même type a été conservé. Mais, à la différence du pressoir d'Ozenay, celui de Martailly, de facture plus fruste et dépourvu de décor, est actionné par une roue à huit rayons et sa maie est pourvue d'une double goulotte.

\section{Les pressoirs à vis centrale}

De dimensions inférieures aux pressoirs à levier, et beaucoup moins encombrants, les pressoirs à vis centrale apparaissent très vraisemblablement en Côte-d'Or viticole dès le $\mathrm{XVI}^{\mathrm{e}}$ siècle. C'est ce que laisse supposer l'analyse des parties anciennes de la cuverie du Clos de Tart, à Morey-Saint-Denis (Côte-d'Or), même si le pressoir a visiblement été très restauré quand sa vis en bois fut remplacée par l'actuelle vis en fer. Ce type de machine se répand dans toute la Bourgogne dès le XVIIe siècle avant de se généraliser au siècle suivant. Toutefois, là encore, aucune des dates portées que nous avons pu relever 
n'est antérieure au XVIII ${ }^{\mathrm{e}}$ siècle. Les pressoirs à vis centrale coexistent avec les pressoirs à levier comme avec les pressoirs à grand point, mais ils étaient surtout utilisés dans les domaines de moindre importance.

Le chêne était utilisé pour le bâti, le mouton, les madriers de la maie, les claies et les cales, mais le frêne était préféré pour le cabestan et le treuil ; la vis étant généralement tournée dans du cormier, bois “ gras ”, à la texture serrée, résistant bien à la torsion.

Le bâti est constitué, selon son importance, de deux ou de quatre poteaux renforcés par des jambes de force, supportant une ou deux traverses hautes assemblées par enfourchements. Ces traverses reçoivent la vis du pressoir. La pression donnée par la vis est transmise aux cales par l'intermédiaire d'une pièce transversale, le mouton.

\section{Les pressoirs à vis actionnée par un étiquet}

Figure 27

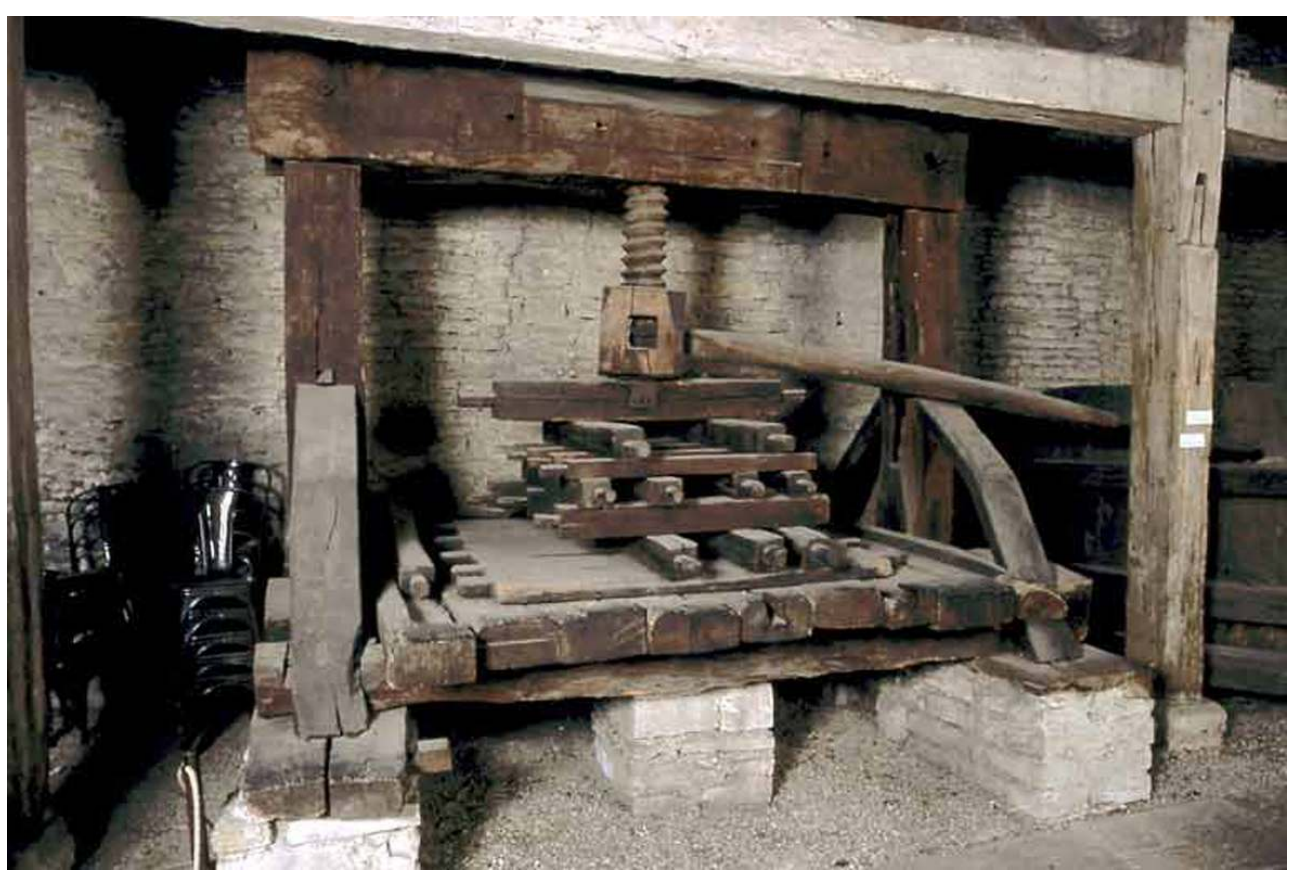

Pressoir à vis centrale et étiquet de Buxy, Saône-et-Loire, conservé au Musée du Vin à Beaune. Vue d'ensemble

Phot. Inv. M. Thierry @ Inventaire général, ADAGP, 2002

La vis de certains pressoirs était actionnée par une simple perche, l'étiquet, engagée dans la mortaise d'une lanterne. Quelques rares pressoirs de ce type (fig. $n^{\circ} 27$ ) ont été conservés, témoin celui de Buxy (Saône-et-Loire), conservé au Musée du Vin à Beaune. 
Figure 28

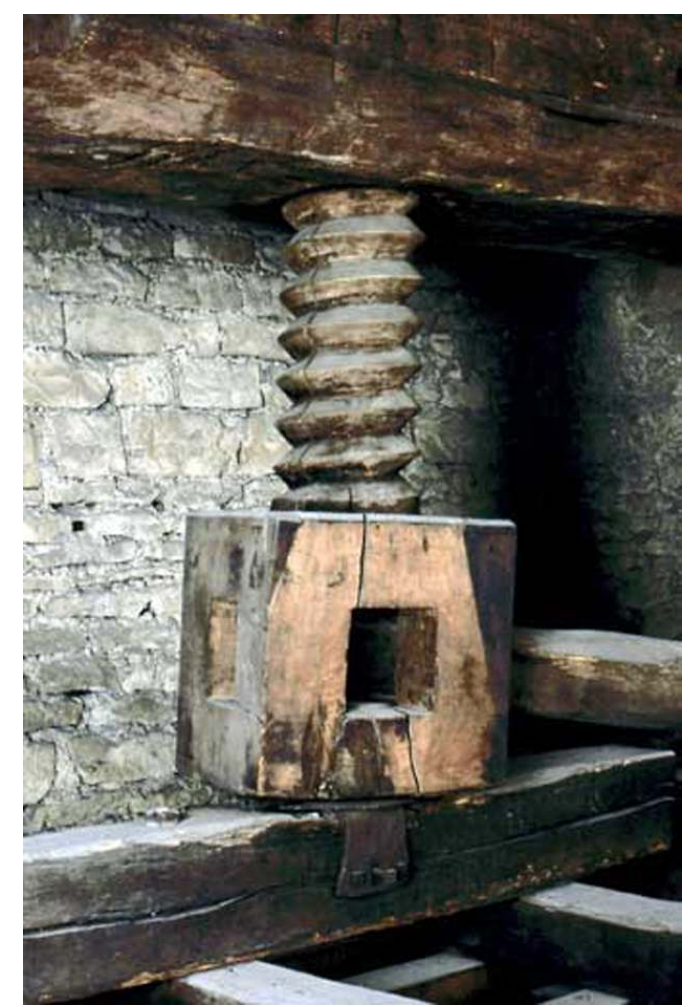

Pressoir à vis centrale et étiquet de Buxy, Saône-et-Loire, conservé au Musée du Vin à Beaune. Détail de la lanterne

Phot. Inv. M. Thierry @ Inventaire général, ADAGP, 2002

Pressoir de petit domaine, il est constitué de deux poteaux renforcés par des jambes de force. Les patins jumelés du chantier reposent sur des murettes maçonnées. La vis, de faible section, était actionnée par deux étiquets engagés dans les mortaises traversantes d'une lanterne cubique (fig. $\mathrm{n}^{\circ}$ 28). Le mouton est équipé de poignées.

Xavier Humbel en signale un autre de même type à Riquewihr, en Alsace.

\section{Les pressoirs à vis centrale et roue de presse}

71 A ce procédé, évidemment très imparfait, au rendement très faible, étaient préférés les systèmes à roue de presse. Celle-ci était mue soit par un cabestan, véritable treuil vertical comparable aux cabestans utilisés dans la marine, soit par un treuil horizontal actionné par une grande calandre munie de chevilles, appelée roue à perroquet. C'est ce dernier type qui a laissé le plus grand nombre de témoignages et qui a, semble-t-il, été le plus utilisé. On le rencontre sur de nombreux sites, du nord de l'Yonne jusqu'à la Côte chalonnaise.

Comme sur les autres pressoirs, la maie, sur laquelle sont entassés les marcs, est constituée de madriers juxtaposés bloqués par des cales entre les poteaux du bâti. Elle est creusée d'une gorge qui reçoit la claie et d'une rigole servant à canaliser le jus qui se déverse par la «([goulotte] : ${ }^{*}$ Goulotte*)».

73 La vis est actionnée par une roue, d'un diamètre variable, la roue de presse ou " roue à gorge". Ses rayons, qui enserrent le pied de la vis, sont généralement dépassants : ils 
guident la corde sur la jante et évitent qu'elle ne tombe au moment du desserrage. Ils permettaient, en outre, d'avoir une action manuelle directe sur la roue pendant les opérations de pressurage. D'ailleurs certaines de ces roues à gorge, et tout particulièrement les roues en fer, sont munies de poignées.

\section{Les pressoirs à cabestan et étiquet}

\section{Figure 29}

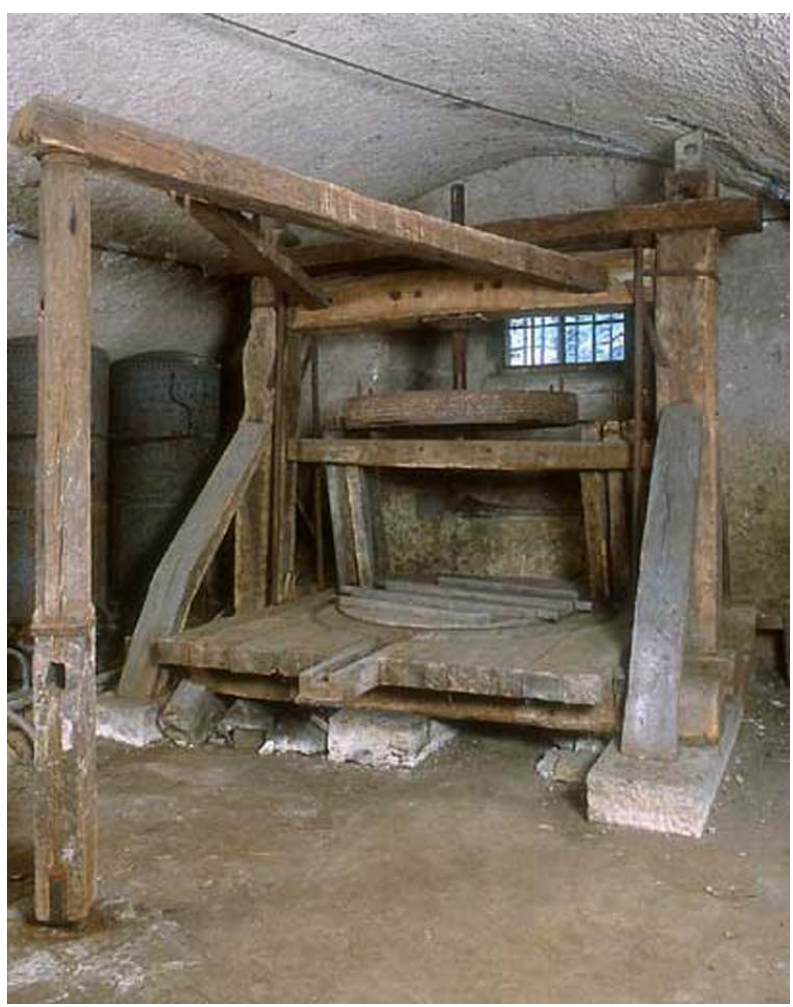

Pressoir à vis centrale et cabestan du château de Coulon, à Mouron-sur-Yonne, Nièvre. Vue d'ensemble, de face

Phot. Inv. M. Thierry @ Inventaire général, ADAGP, 2001

$74 \mathrm{Au}$ château de Coulon (fig. $\mathrm{n}^{\circ}$ 29), à Mouron-sur-Yonne, (Nièvre), la roue de presse est actionnée par un treuil vertical, le cabestan. Ce dernier est relié à la traverse haute du bâti par deux pièces de chêne disposées en triangle, et il est ancré au sol par une crapaudine en fer forgé qui pivote dans un bloc en pierre de taille. 
Figure 30

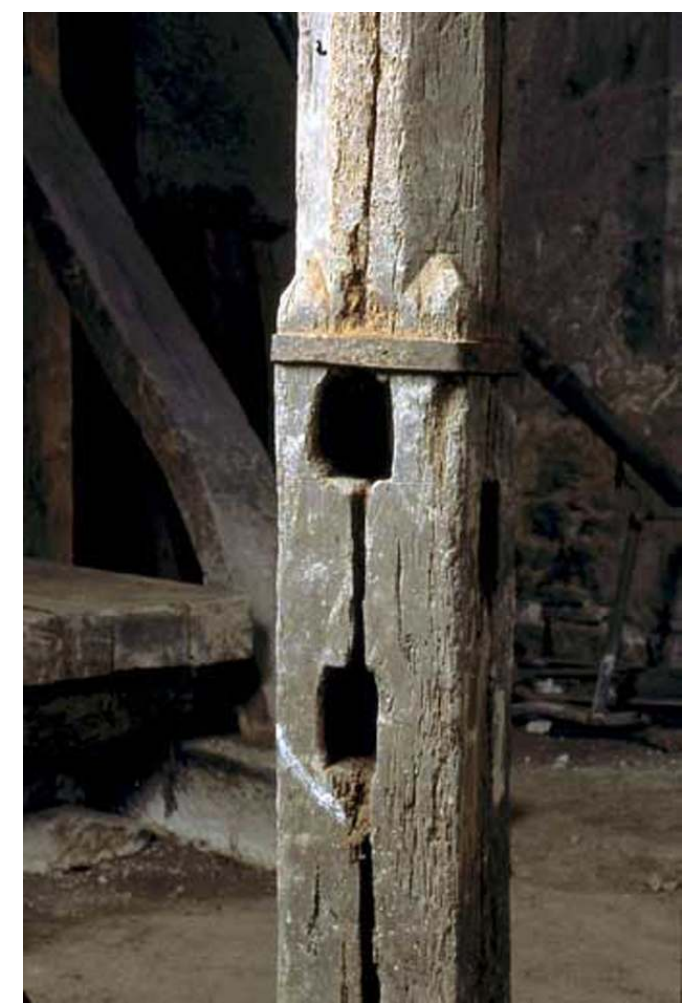

Pressoir à vis centrale et cabestan du château de Coulon, à Mouron-sur-Yonne, Nièvre. Détail de la lanterne du cabestan

Phot. Inv. M. Thierry @ Inventaire général, ADAGP, 2001

75 Il pouvait être actionné par trois étiquets, la lanterne du treuil étant traversée (fig. $\mathrm{n}^{\circ}$ 30) par trois mortaises superposées. La face antérieure du mouton porte la date gravée 1776.

76 L'encombrement de ces pressoirs à vis centrale est relativement réduit comparé à celui des grandes machines évoquées plus haut. Il est de 3,75 $\mathrm{m}$ au carré pour le pressoir du château de Coulon et le diamètre de la roue de presse est de 1,60 m, mais la surface de la maie, qui dépasse $8 \mathrm{~m}^{2}$, est identique à celle des maies des pressoirs d'Ozenay.

On connaît mal la nature des cultures de ce domaine dont le château fut reconstruit vers 1550, mais un document de 1718 nous apprend qu'une des parcelles appelée “ la vigne neuve" a produit pas moins de 40 feuillettes, ce qui équivaut à environ 5500 litres de vin. Cette production suffit à expliquer la présence de ce pressoir qui était à l'origine remisé dans les communs, peut-être avec d'autres pressoirs. Il a été, depuis, transporté dans le cellier d'une des ailes du logis. 
Figure 31

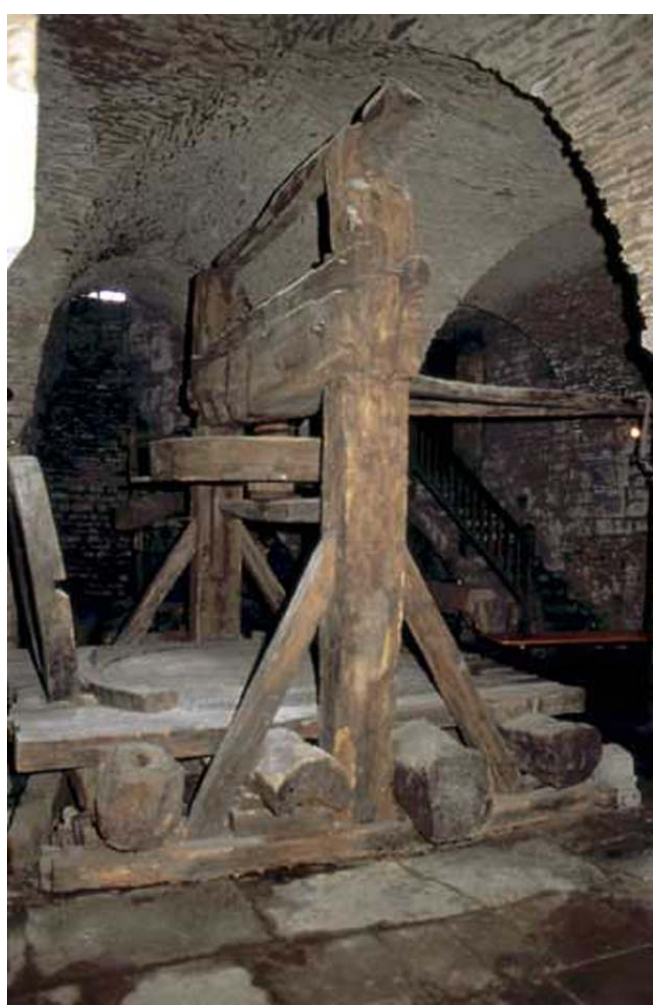

Pressoir à vis centrale et cabestan de l'ancienne abbaye de Saint-Martin-de-Cure, à Domecy-sur-Cure, Yonne, conservé dans une des salles de la mairie de Vézelay. Vue d'ensemble

Phot. Inv. J.L. Duthu (C) Inventaire général, ADAGP, 2002.

Le pressoir de l'ancienne abbaye de Saint-Martin-de-Cure, à Domecy-sur-Cure (Yonne) est du même type.

Il est aujourd'hui conservé dans une des salles voûtées d'un bâtiment du XIII siècle attenant à la mairie de Vézelay (fig. $n^{\circ} 31$ ). Il est cependant plus massif que celui de Coulon et sa roue de presse comme sa maie sont plus importantes. Le cabestan n'était pourtant actionné que par deux étiquets. Il a en outre conservé sa roue de presse en bois, cette dernière ayant été fréquemment remplacée par une roue de métal sur ce type de machine. La longueur hors tout du pressoir est de $4 \mathrm{~m}$, le diamètre de la roue de presse atteint $2 \mathrm{~m}$ et la surface de la maie $10,20 \mathrm{~m}^{2}$.

\section{Les pressoirs à treuil et roue à perroquet}

En raison de la rareté des témoignages qui subsistent, on peut penser que ces pressoirs à vis centrale et cabestan ont précédé les modèles à treuil horizontal et roue à perroquet. A ce jour, en effet, on n'en a repéré que trois, le troisième, provenant de Chaudenay-surDheune, en Saône-et-Loire, étant exposé au Musée du Vin à Beaune.

Beaucoup plus répandus sont les pressoirs à treuil horizontal manœuvré par une roue à rayons, appelée roue à perroquet en raison des longues et nombreuses chevilles qui traversent la jante. Ces fortes chevilles permettaient à plusieurs aides d'avoir une action simultanée sur la roue. Comme le cabestan, le treuil et la roue à perroquet sont indépendants du bâti du pressoir avec lequel ils ne sont pas toujours solidarisés. A 
Baubigny, au hameau d'Evelle, le treuil et la calandre sont directement ancrés dans les murs de la cuverie, ou d'ailleurs une trappe ménagée dans le plafond permettait à un aide supplémentaire d'actionner la calandre depuis le comble. A La Bussière-sur-Ouche, le treuil est fixé d'un côté dans la maçonnerie du cellier et de l'autre dans un poteau arrimé à la charpente.

Pour ménager la roue de presse et assurer une tension régulière de la corde, celle-ci pouvait s'enrouler à une extrémité du treuil et se dérouler simultanément de l'autre. Ce système, dit “ à corde continue ", a sans doute été adopté sur les plus grandes machines comme en témoigne la présence des crochets qui servaient à attacher les deux extrémités de la corde, au Clos de Tart, ou encore à l'abbaye de la Bussière-sur-Ouche.

Il est intéressant de constater que l'évolution supposée des pressoirs à vis centrale est comparable à celle des grands pressoirs à levier sur lesquels ont été abandonnés les étiquets au profit des roues à taquets, plus résistantes, et dont le rendement était supérieur.

Figure 32

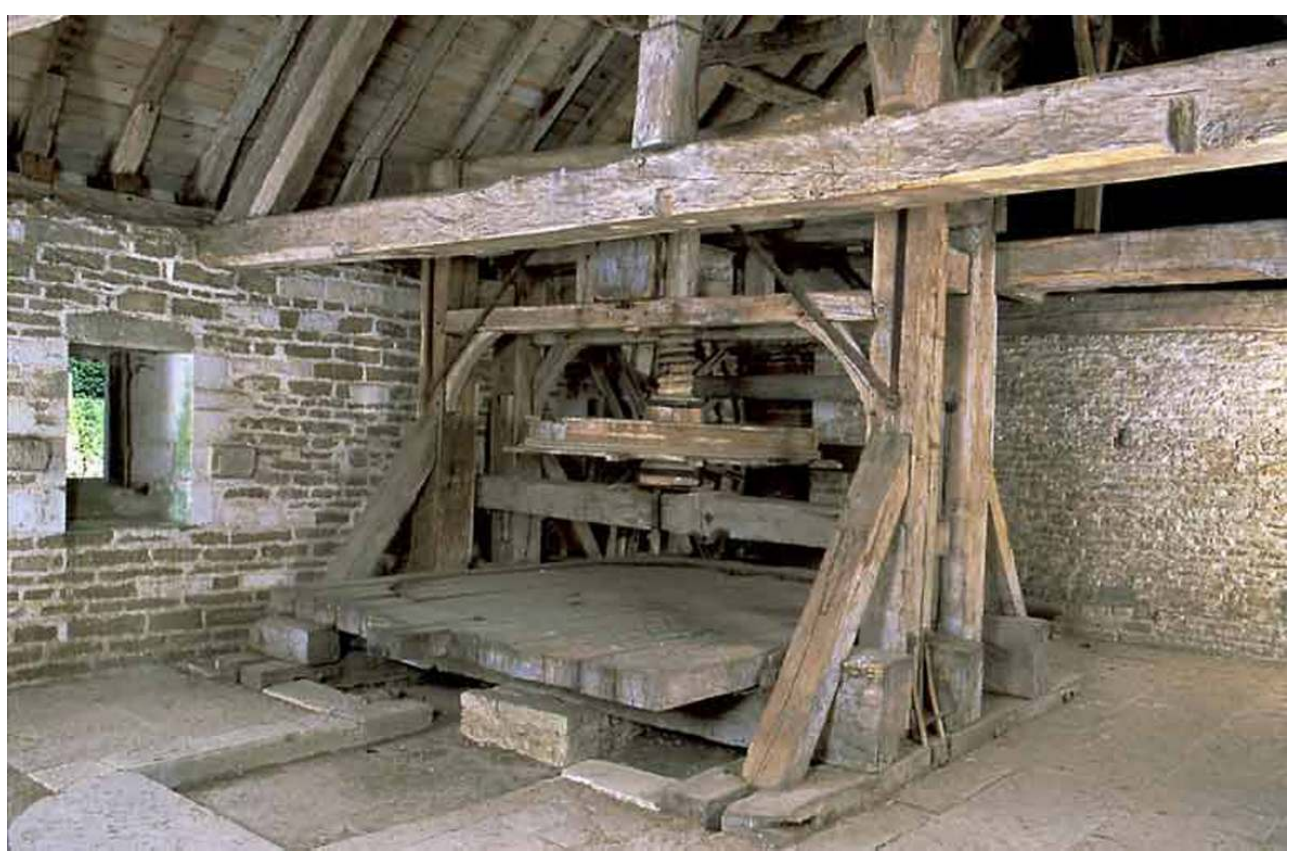

Pressoir à vis centrale, à treuil et roue à perroquet, de l'abbaye de La Bussière-sur-Ouche, Côte-d'Or. Vue densemble

Phot. Inv. M. Thierry @ Inventaire général, ADAGP, 2002

Le grand pressoir de l'ancienne abbaye de La Bussière-sur-Ouche, en Côte-d'Or (fig. n - 32), est une des plus anciennes machines de ce type conservées en Bourgogne. Elle est remisée dans sa cuverie d'origine, au rez-de-chaussée surélevé d'un bâtiment allongé, isolé à l'ouest de l'abbaye. Comme le grand réfectoire, le colombier et le moulin, ce cellier, qui vient d'être restauré par le Service régional des Monuments Historiques de Bourgogne, a été construit au XIII ${ }^{\mathrm{e}}$ siècle, période de plein essor de l'abbaye.

On accède à la cuverie par un plan incliné qui conduit à la porte charretière ménagée dans le mur-pignon sud. Le pressoir est remisé à l'arrière de la cuverie. 


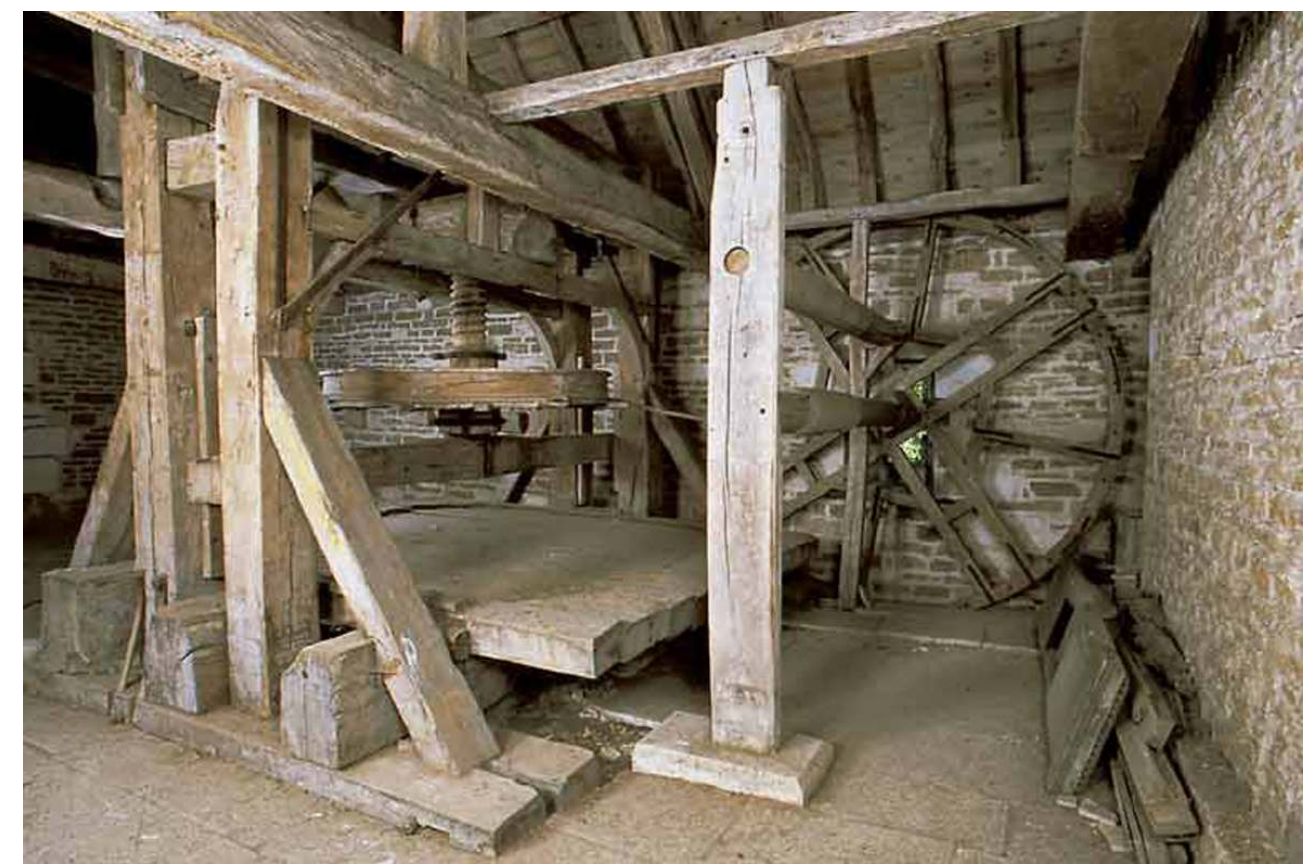

Pressoir à vis centrale, à treuil et roue à perroquet, de l'abbaye de La Bussière-sur-Ouche, Côte-d'Or. Vue de trois-quarts postérieurs

Phot. Inv. M. Thierry @ Inventaire général, ADAGP, 2002

Remisé au fond de la cuverie, ce pressoir est certainement l'un des plus intéressants de Bourgogne et l'un des plus homogènes. Ses dimensions sont impressionnantes. La lourde roue de presse, en bois, de 2,30 $\mathrm{m}$ de diamètre (fig. $\mathbf{n}^{\circ} \mathbf{3 3}$ ), est mue par une corde continue qui s'enroule sur un treuil ancré à l'arrière du pressoir. 
Figure 34

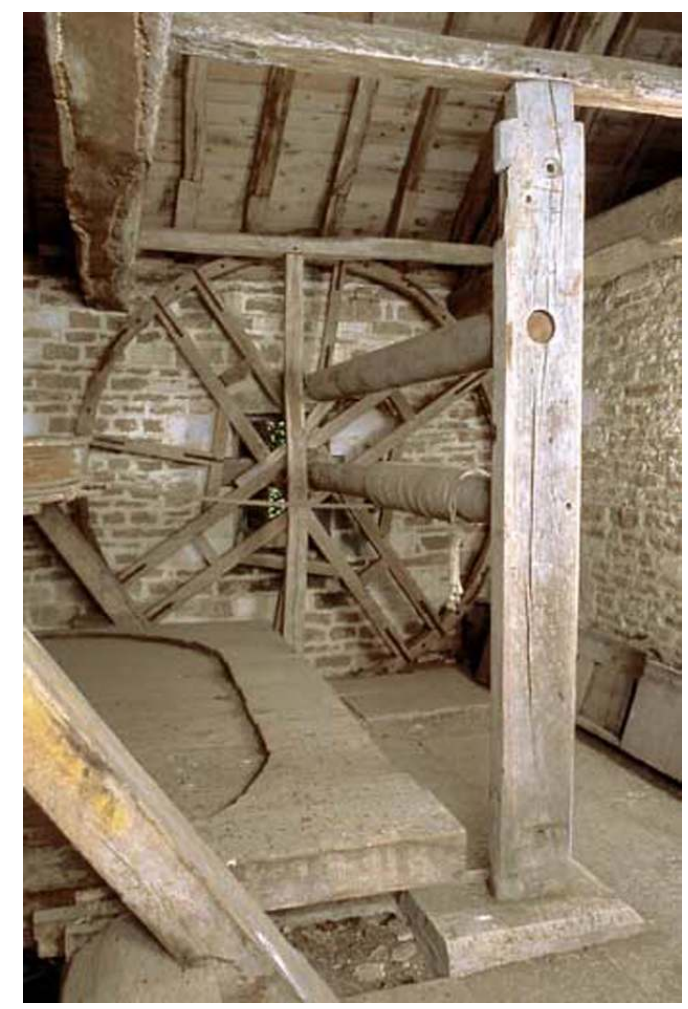

Pressoir à vis centrale, à treuil et roue à perroquet, de l'abbaye de La Bussière-sur-Ouche, Côte-d'Or. Treuils et roue à perroquet, détail

Phot. Inv. M. Thierry (c) Inventaire général, ADAGP, 2002

Le treuil est actionné par une grande roue à perroquet à 8 rayons, de 3,90 $\mathrm{m}$ de diamètre. Il est surmonté d'un deuxième rouleau qui permettait de surélever la corde quand la roue de presse se trouvait en partie haute, au début de la pressée. Les puissants poteaux du bâti sont doublés et fortement épaulés (fig. $\mathbf{n}^{\circ}$ 34). La surface de la maie est de $17 \mathrm{~m}^{2}$. Elle est supérieure aux maies les plus importantes des grands pressoirs à levier du Clos de Vougeot. Pas de date portée, si ce n'est un graffiti de 1819 qui pourrait indiquer une réparation, mais des marques de pose confirment l'homogénéité de ce pressoir qui ne semble pas avoir été l'objet de réfections importantes. 


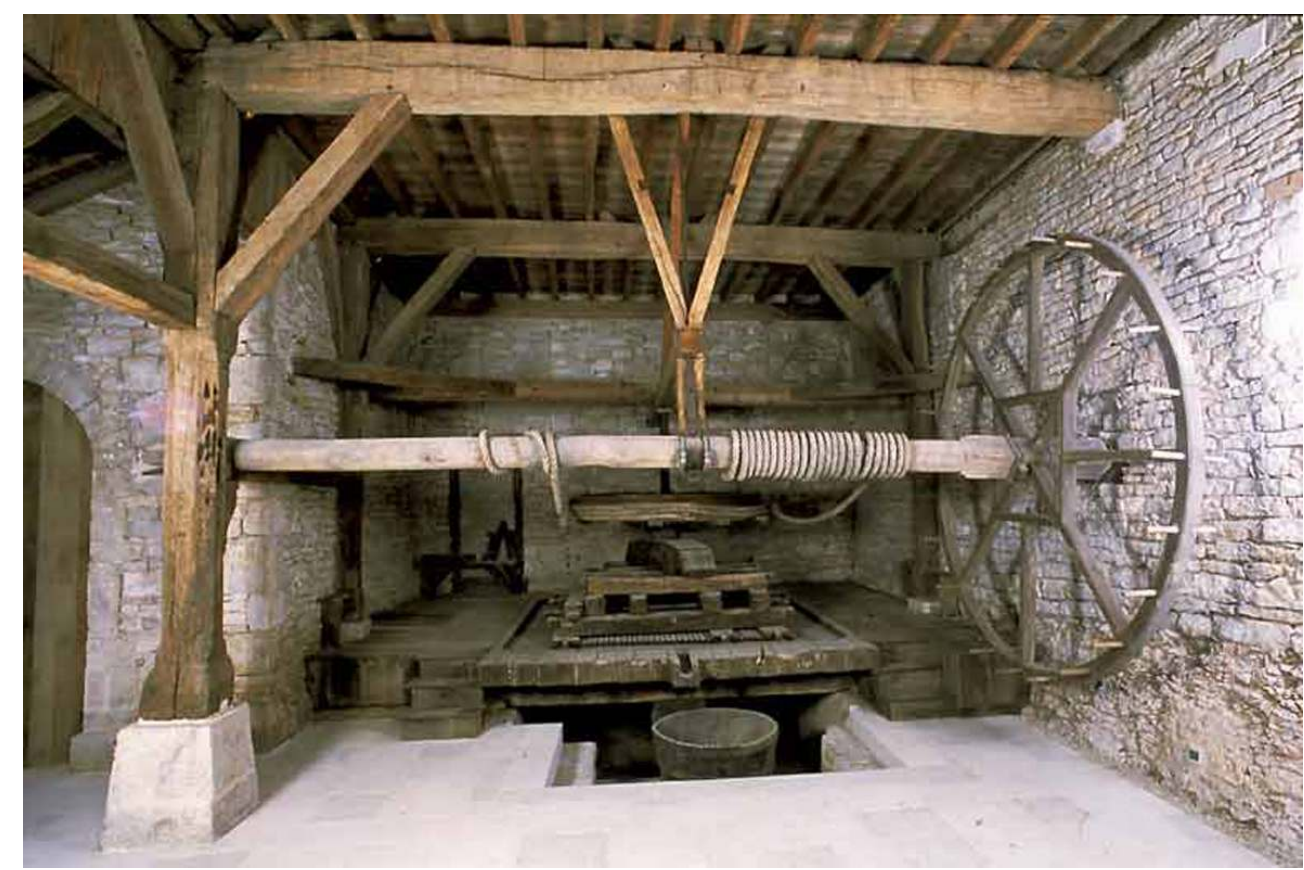

Pressoir à vis centrale, à treuil et roue à perroquet, du Clos de Tart, à Morey-Saint-Denis, Côte-d'Or. Vue d'ensemble

Phot. Inv. M. Thierry @ Inventaire général, ADAGP, 2002

Le Clos de Tart (fig. $\mathbf{n}^{\circ}$ 35), à Morey-Saint-Denis, en Côte-d'Or, ancienne dépendance de l'abbaye bénédictine de Tart-le-Haut, conserve une machine du même type, remisée dans ce qui paraît être sa cuverie d'origine dont la charpente date visiblement de la fin du XVIe siècle. Elle a été en revanche très restaurée, sans doute quand l'ancienne vis en bois fut remplacée par l'actuelle vis en fer: le mouton a été refait et les madriers qui retiennent la vis en partie haute sont en résineux. En outre, la grande calandre à perroquet $a$, elle aussi, été très vraisemblablement refaite. 


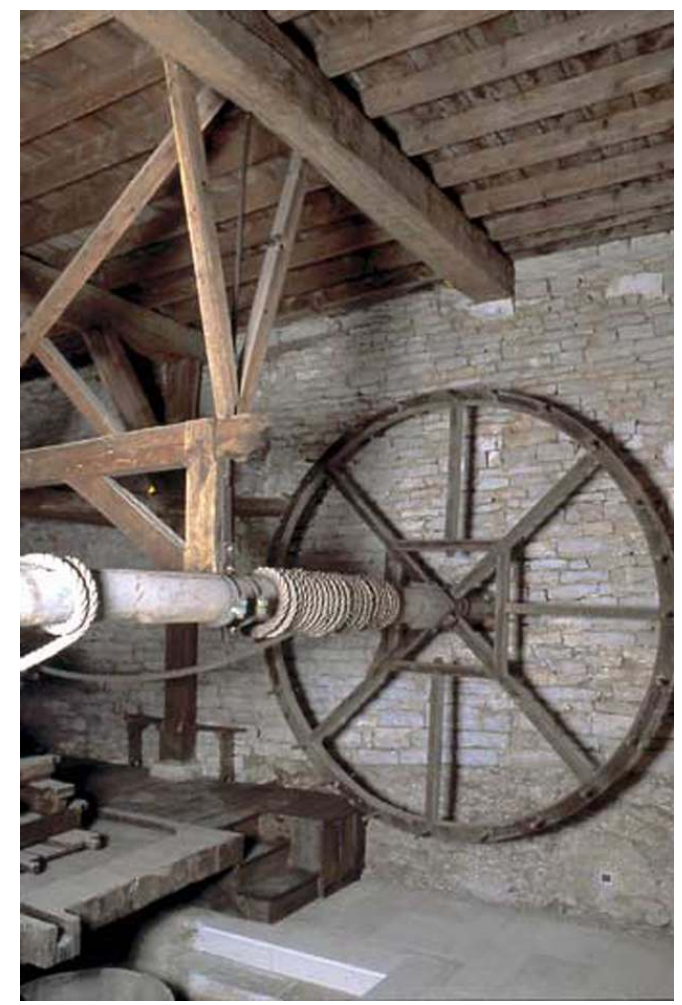

Pressoir à vis centrale, à treuil et roue à perroquet, du Clos de Tart, à Morey-Saint-Denis, Côte-d'Or. Treuil et roue à perroquet, détail

Phot. Inv. M. Thierry (c) Inventaire général, ADAGP, 2002

C'est cependant un précieux témoignage des grandes machines qui étaient utilisées dans les domaines des abbayes. D'autre part, l'utilisation du système (fig. $\mathbf{n}^{\circ}$ 36) dit «à corde continue » est bien attestée par le très long treuil de plus de $6 \mathrm{~m}$ sur lequel les crochets en fer forgé, qui retiennent les deux extrémités de la corde, sont encore en place.

Après l'exceptionnel pressoir de l'abbaye de la Bussière-sur-Ouche, c'est l'un des plus grands pressoirs bourguignons à vis centrale. Les diamètres de la roue de presse et de la roue à perroquet sont respectivement de $2,20 \mathrm{~m}$ et de $3,30 \mathrm{~m}$, la surface de la maie atteignant $13,60 \mathrm{~m}^{2}$. 


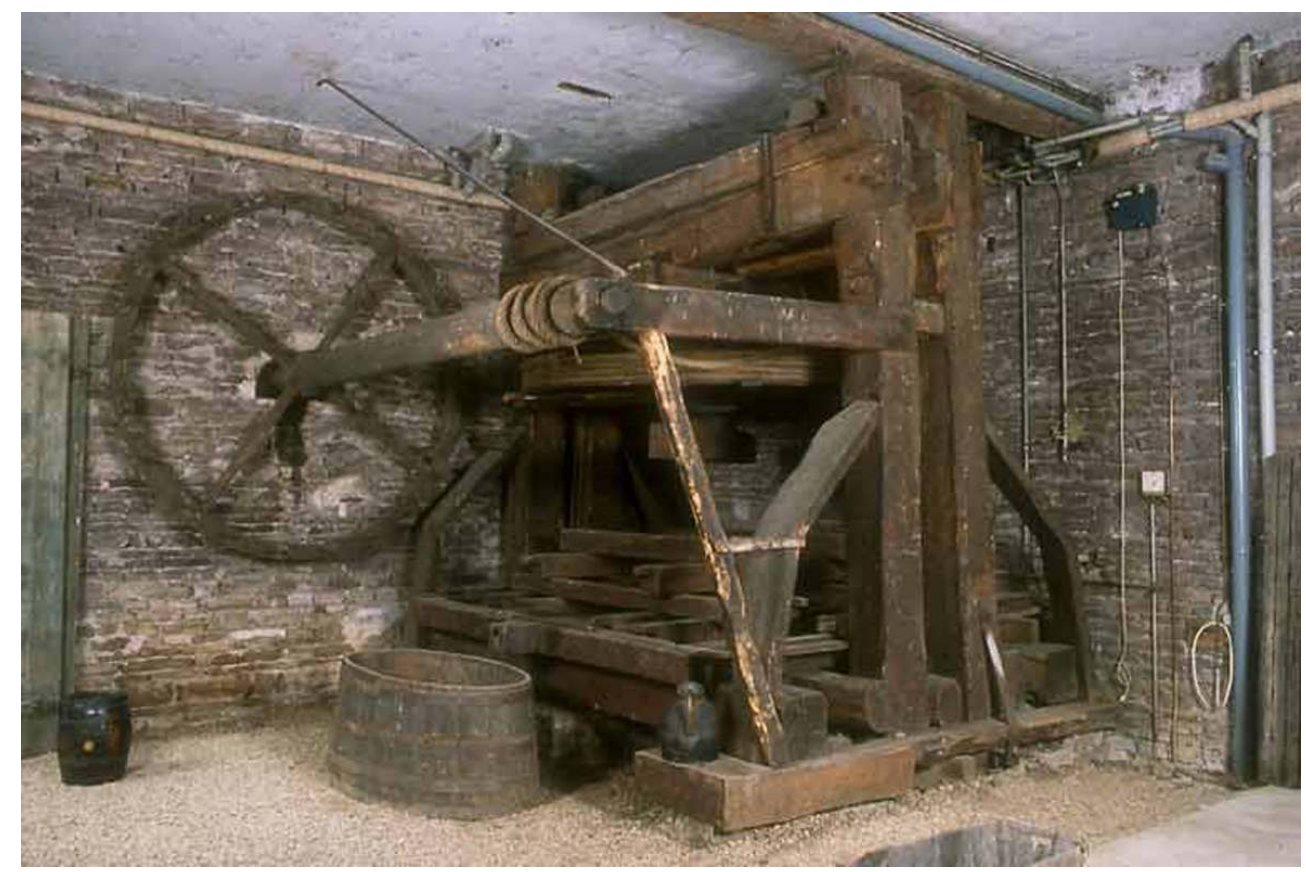

Pressoir à vis centrale, à treuil et roue à perroquet, du château de Demigny, Saône-et-Loire. Vue d'ensemble

Phot. Inv. M. Thierry (c) Inventaire général, ADAGP, 2002

91 La structure de toutes ces machines est la même, mais, sur les plus importantes, comme à La Bussière-sur-Ouche ou encore au château de Demigny (fig. $\mathbf{n}^{\circ}$ 37), en Saône-et-Loire, les poteaux du bâti sont doublés. Les extrémités du mouton, habituellement guidées dans les feuillures des poteaux, se déplacent alors entre les poteaux jumelés qu'épaulent de longues et grêles jambes de force, coudées. La date 1777 est gravée en chiffres romains sur la face antérieure du mouton.

92 Le château de Demigny, situé au sud-est de la côte de Beaune, en Saône-et-Loire, fut reconstruit vers 1805 , à une soixantaine de mètres de l'ancienne forteresse. C'est Théodore Foudras, le marquis aux célèbres écrits cynégétiques, qui acheva les aménagements intérieurs et créa les jardins.

93 Un plan terrier de 1785 montre que le château était alors entouré de vignes. Les communs qui abritent aujourd'hui le pressoir ont été remaniés au XIX ${ }^{\mathrm{e}}$ siècle. C'est à cette époque que le pressoir fut transporté dans sa remise actuelle. 
Figure 38

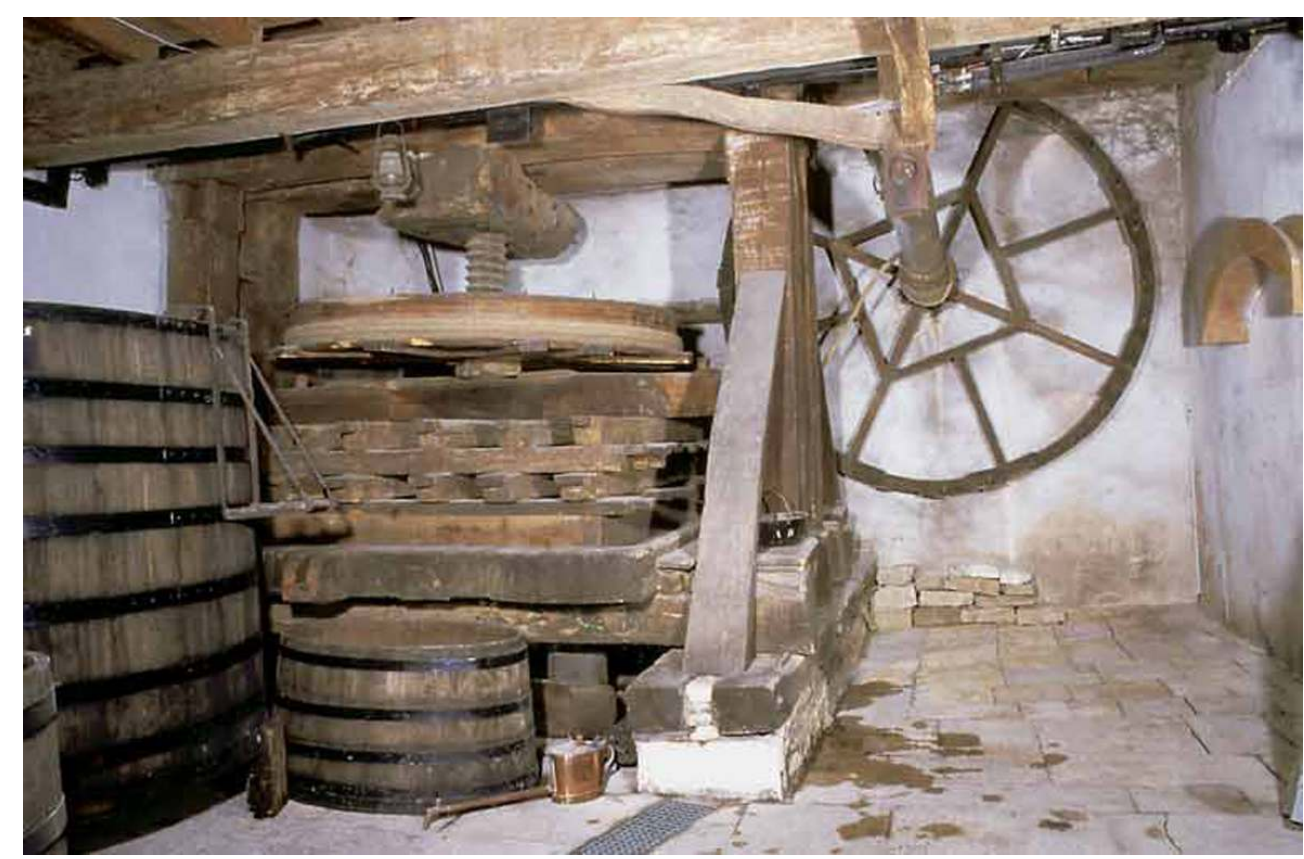

Pressoir à vis centrale, à treuil et roue à perroquet, du domaine Douhairet-Porcheret, à Monthelie, Côted'Or. Vue d'ensemble, de face

Phot. Inv. J.L. Duthu @ Inventaire général, ADAGP, 2002

Le domaine Douhairet-Porcheret de Monthelie, dans les Côtes de Beaune, conserve un pressoir à vis centrale (fig. $\mathbf{n}^{\circ} \mathbf{3 8}$ ) qui compte parmi les plus importants de la Côte. Ce domaine familial à cour fermée, construit à la fin du XVIII ${ }^{\mathrm{e}}$ siècle, communique avec la rue par un passage couvert. La remise fait face au logis et s'ouvre largement sur la cour par une porte charretière à linteau de bois. Le pressoir, contemporain de la construction du domaine, est toujours remisé au fond de la cuverie, à son emplacement d'origine. C'est une grande machine, à poteaux de bâti jumelés. La vis en bois, d'origine, qui avait été déposée et remplacée par une vis en fer, fut remontée par les actuels propriétaires. Une inscription portée à la craie blanche sur un des poteaux du bâti indique que le pressoir a “ été arrêté le 12 octobre 1933 ”. 
Figure 39

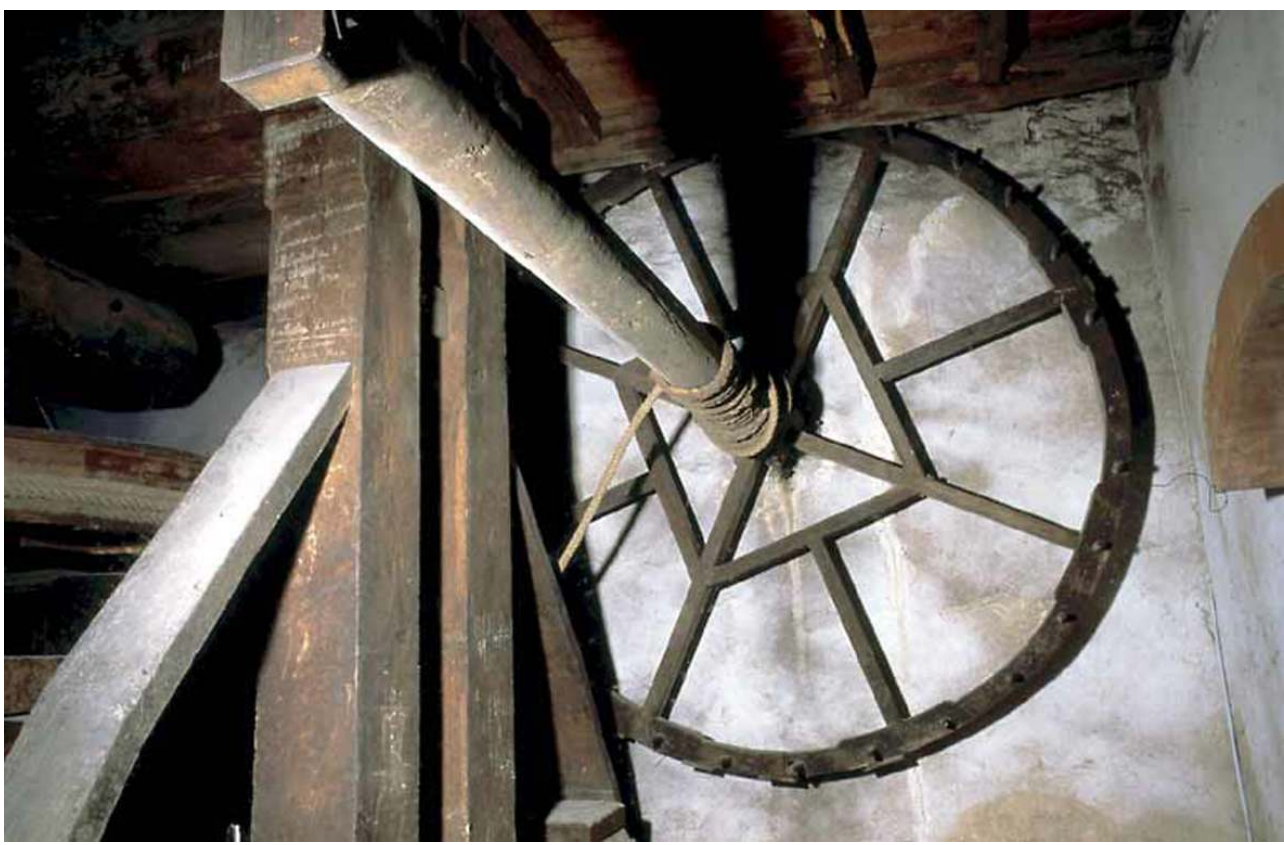

Pressoir à vis centrale, à treuil et roue à perroquet, du domaine Douhairet-Porcheret, à Monthelie, Côted'Or. Treuil et roue à perroquet, détail

Phot. Inv. J.L. Duthu @ Inventaire général, ADAGP, 2002

95 La roue de presse, hérissée de 12 rayons, mesure 2,60 $\mathrm{m}$ de diamètre, la roue à perroquet latérale, à 8 rayons, $3,40 \mathrm{~m}$ (fig. $\mathbf{n}^{\circ}$ 39) et la surface de la maie dépasse $12 \mathrm{~m}^{2}$.

\section{Les pressoirs à treuil et roue à écureuil}


Figure 40

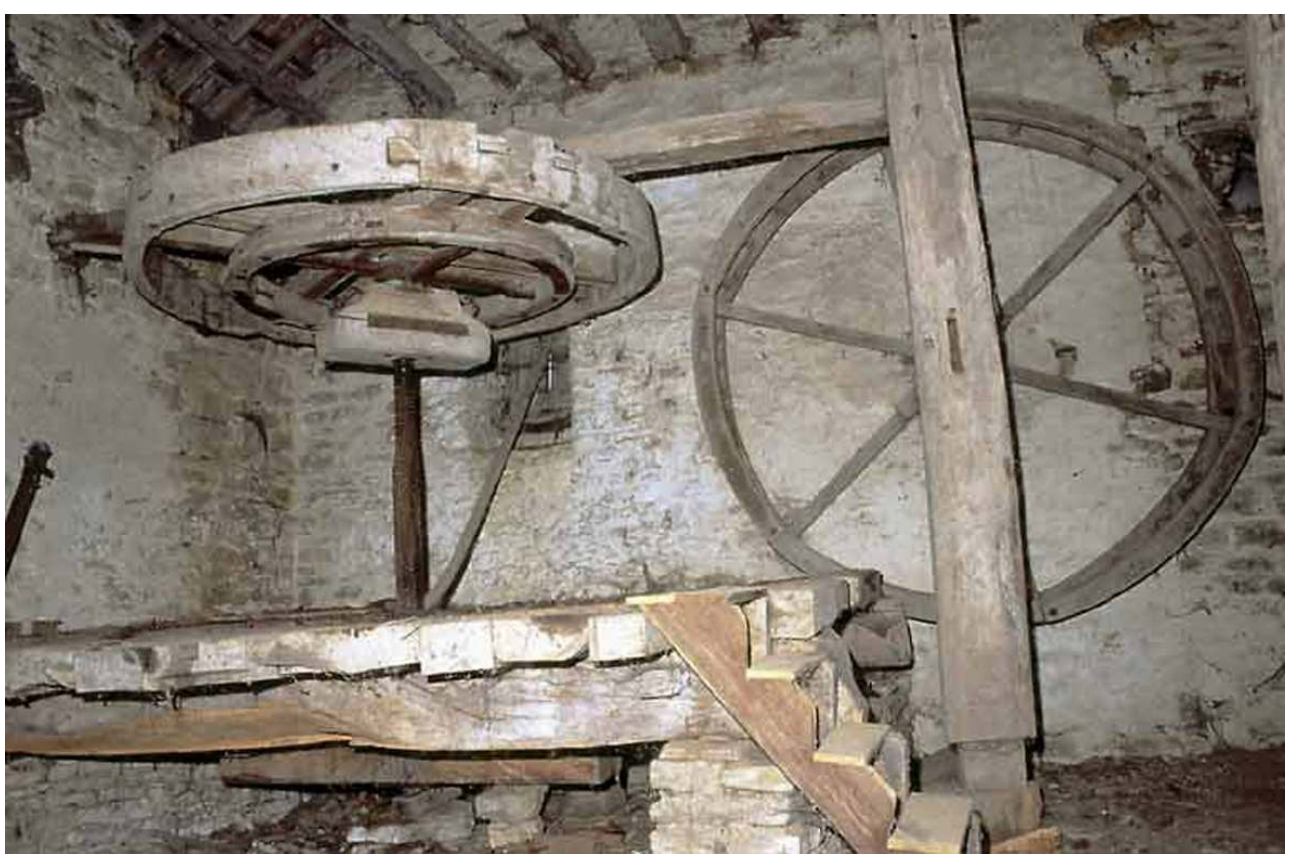

Pressoir à vis centrale et roue à écureuil, du domaine de Vaufron, à Saint-Père-sous-Vézelay, Yonne. Vue d'ensemble

Phot. Inv. J.L. Duthu ( Inventaire général, ADAGP, 2002

Dernière grande variante de ces pressoirs à vis centrale : ceux dont la roue de presse est actionnée par une roue à double jante appelée roue à écureuil. Le pressoir de Saint-Pèresous-Vézelay, au domaine de Vaufron, est un des très rares exemplaires de ce type (fig. $\mathrm{n}$ ○ 40) : les deux jantes jumelées de la grande roue à écureuil, qui ne mesure pas moins de 2,90 $\mathrm{m}$ de diamètre, sont solidarisées par des rayons sur lesquels marchait un enfant. 


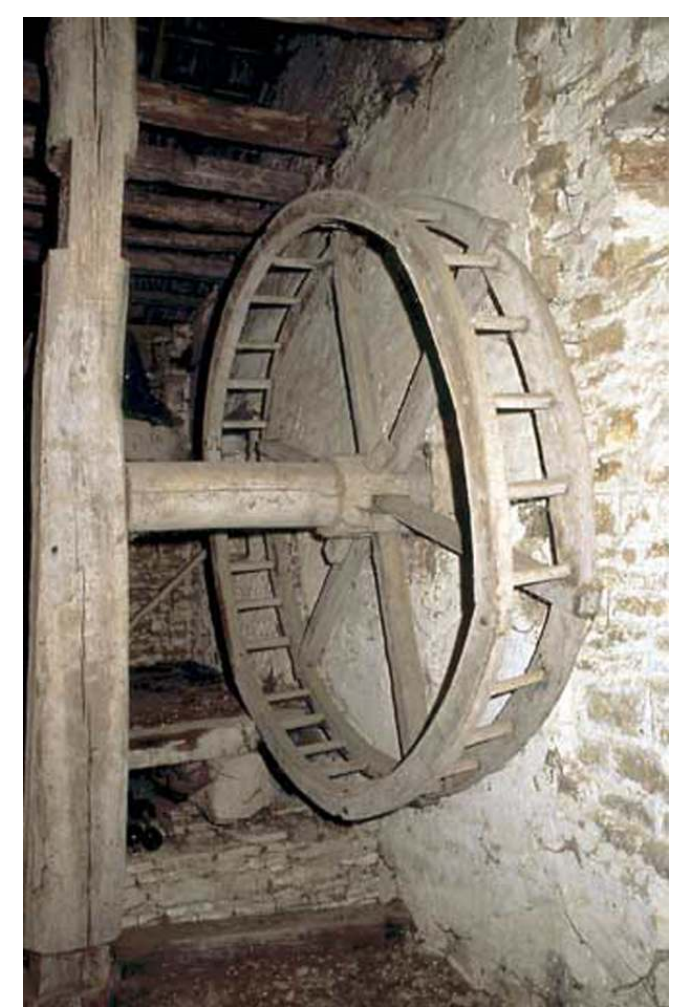

Pressoir à vis centrale et roue à écureuil, du domaine de Vaufron, à Saint-Père-sous-Vézelay, Yonne. Détail de la roue à écureuil

Phot. Inv. J.L. Duthu @ Inventaire général, ADAGP, 2002

97 Un aide pouvait, en outre, actionner manuellement la roue à écureuil de l'extérieur. La roue de presse est ici doublée par une roue plus grande pourvue de poignées. C'est autour de la plus petite roue à gorge que s'enroulait la corde tendue par le treuil. La surface de la maie est d'environ $10 \mathrm{~m}^{2}$ (fig. $\mathrm{n}^{\circ} 41$ ).

98 La cuverie, de plan en L, est parcourue au sol par trois rigoles en pierre de taille qui convergent vers un collecteur central circulaire. Ces rigoles permettaient d'acheminer le jus de presse de plusieurs pressoirs qui se déversait directement dans une cuve située dans la cave, au sous-sol.

Ce petit domaine viticole du Vézelien, dont les bâtiments principaux ont été construits au $\mathrm{XVII}$ siècle, a subi d'importantes réfections un siècle plus tard. C'est peut-être de cette époque que date ce pressoir d'un type exceptionnel en Bourgogne.

\section{Les pressoirs à roue à écureuil et engrenages}


Figure 42

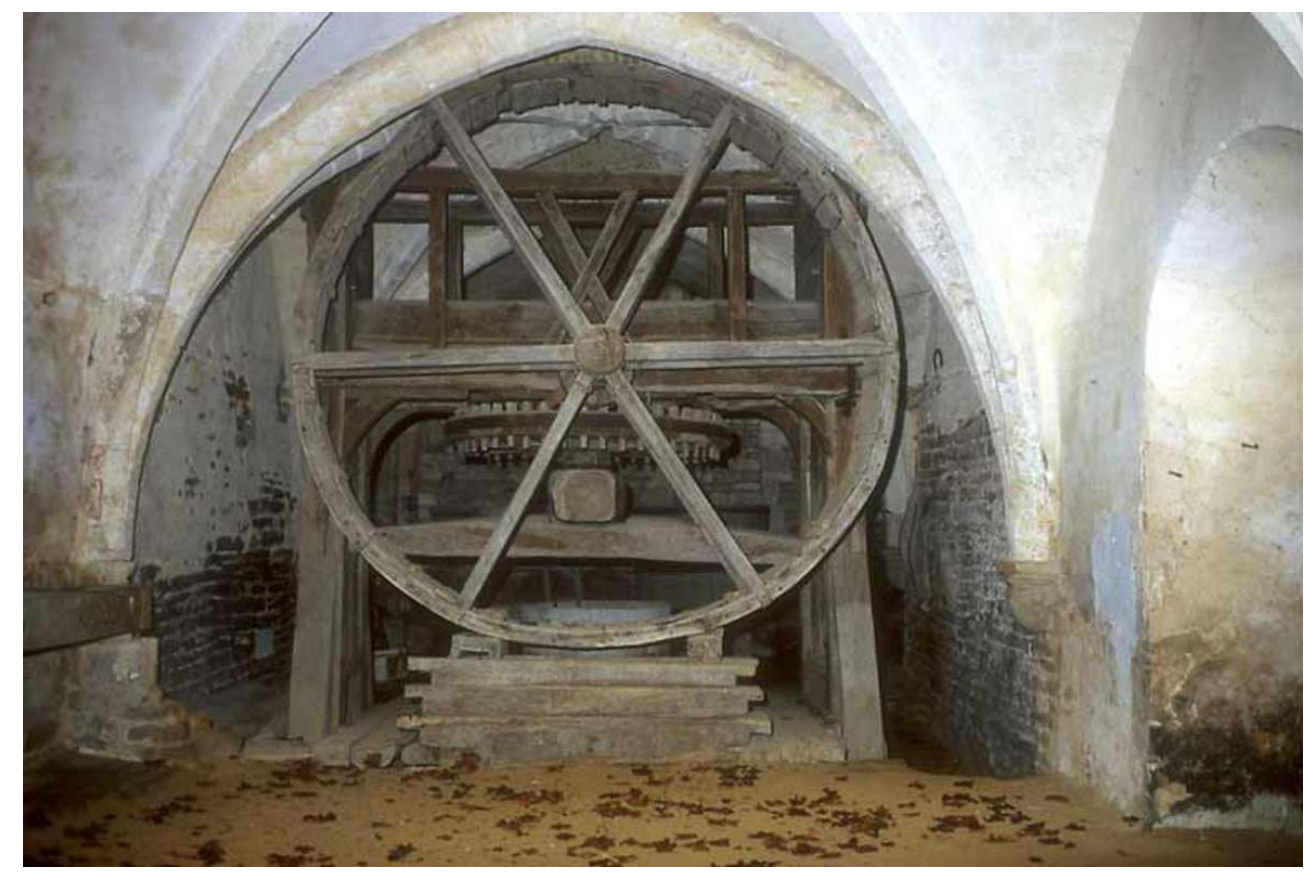

Pressoir à roue à écureuil et engrenages, de l'ancienne abbaye de Molesmes, Yonne. Vue d'ensemble, de face

Phot. Inv. F. Portet ( Inventaire général, ADAGP, 2000

100 Autre variante très rare du pressoir à vis centrale, le pressoir à roue à écureuil et engrenages, dont seulement deux exemplaires sont connus en Bourgogne. L'un est situé à Montboulon, dans l'Yonne, l'autre est conservé dans le vaste cellier voûté (fig. $n^{\circ} 42$ ) du XIII ${ }^{e}$ siècle de l'ancienne abbaye bénédictine de Molesmes, en Côte-d'Or. 
Figure 43

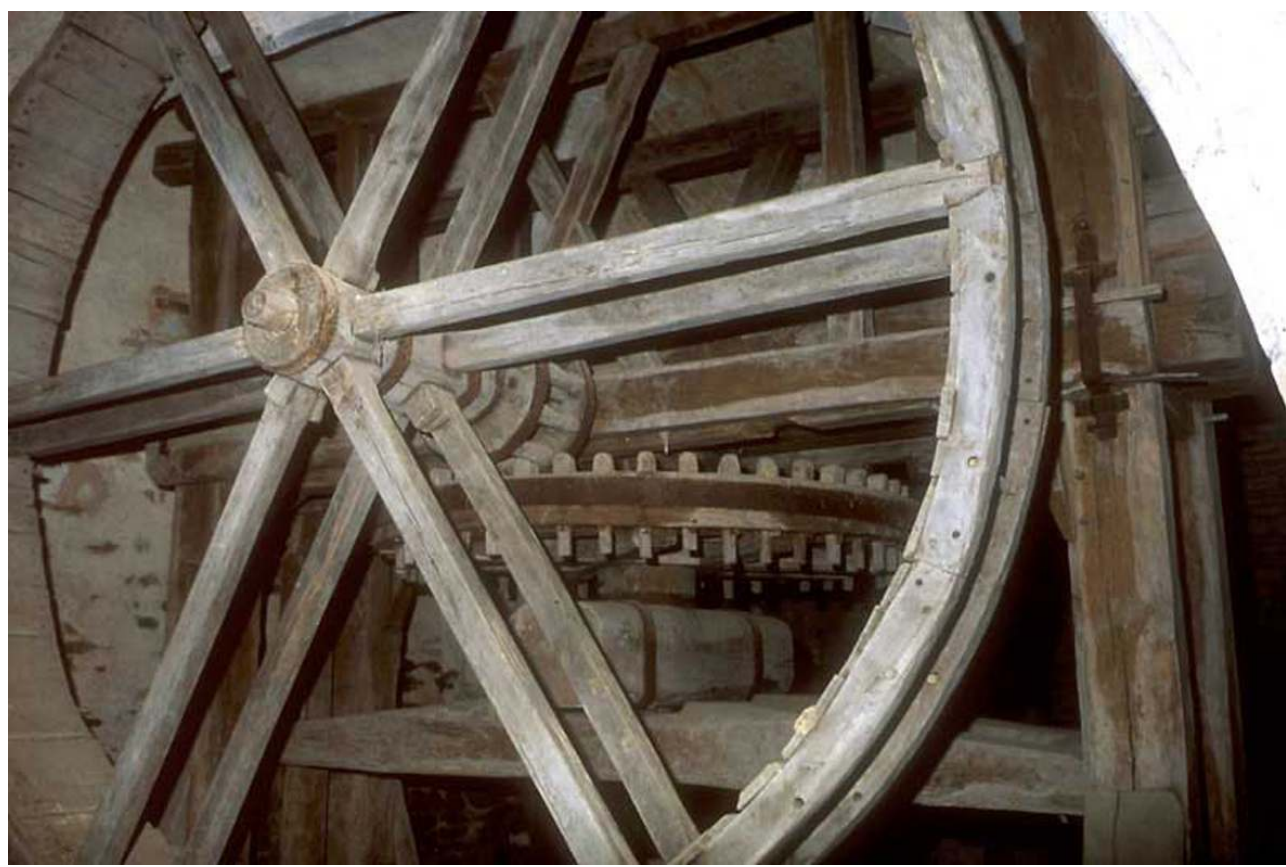

Pressoir à roue à écureuil et engrenages, de l'ancienne abbaye de Molesmes, Yonne. Détail de la roue Phot. Inv. F. Portet (c) Inventaire général, ADAGP, 2000

Treuil et corde disparaissent et la roue de presse, dentée, à pignons de bois, bien connue dans les moulins sous le nom de "hérisson" (fig. n 43), est actionnée par une grande roue verticale, dite "à écureuil", par l'intermédiaire d'une lanterne prolongeant le moyeu de la roue. Cette grande machine, qui ne semble pas avoir été abondamment reproduite, annonce déjà ce que deviendront, quelques décennies plus tard, les pressoirs modernes à engrenages métalliques.

102 Le bâtiment des celliers et le pressoir ont été inscrits à l'Inventaire supplémentaire des Monuments historiques en 1985.

\section{Le " casse-coué " et les pressoirs domestiques}

103 A côté de ces grands pressoirs, souvent communautaires, les petits pressoirs domestiques, fragiles et de faible rendement, ont laissé peu de souvenirs. Les rares exemplaires qui subsistent de la période pré-industrielle sont de type à levier, à corde tendue au moyen d'un treuil. Ces pressoirs à perche que l'on désignait du terme évocateur de "casse-coué " (casse-cou), étaient constitués d'un chantier isolé du sol par 4 pieds, et d'une perche tendue par une corde au moyen d'un treuil à cliquet fixé à l'avant du chantier. La perche était relevée au moyen d'une simple poulie par une corde fixée à une poutre de la cuverie ; les marcs étaient entassés dans une claie posée sur la maie.

Ces petits pressoirs domestiques étaient fréquents sur tous les sites voués à la polyviticulture. Ils étaient présents dans le Vézelien, les Vaux d'Yonne et même dans le Valde-Saône où quelques rares exemplaires subsistent encore au fond des remises. Les pressoirs à perche de Saint-Aubin-des-Chaumes, au hameau de Charancy, dans la Nièvre et celui de Broin, en Côte-d'Or en témoignent. 
Figure 44

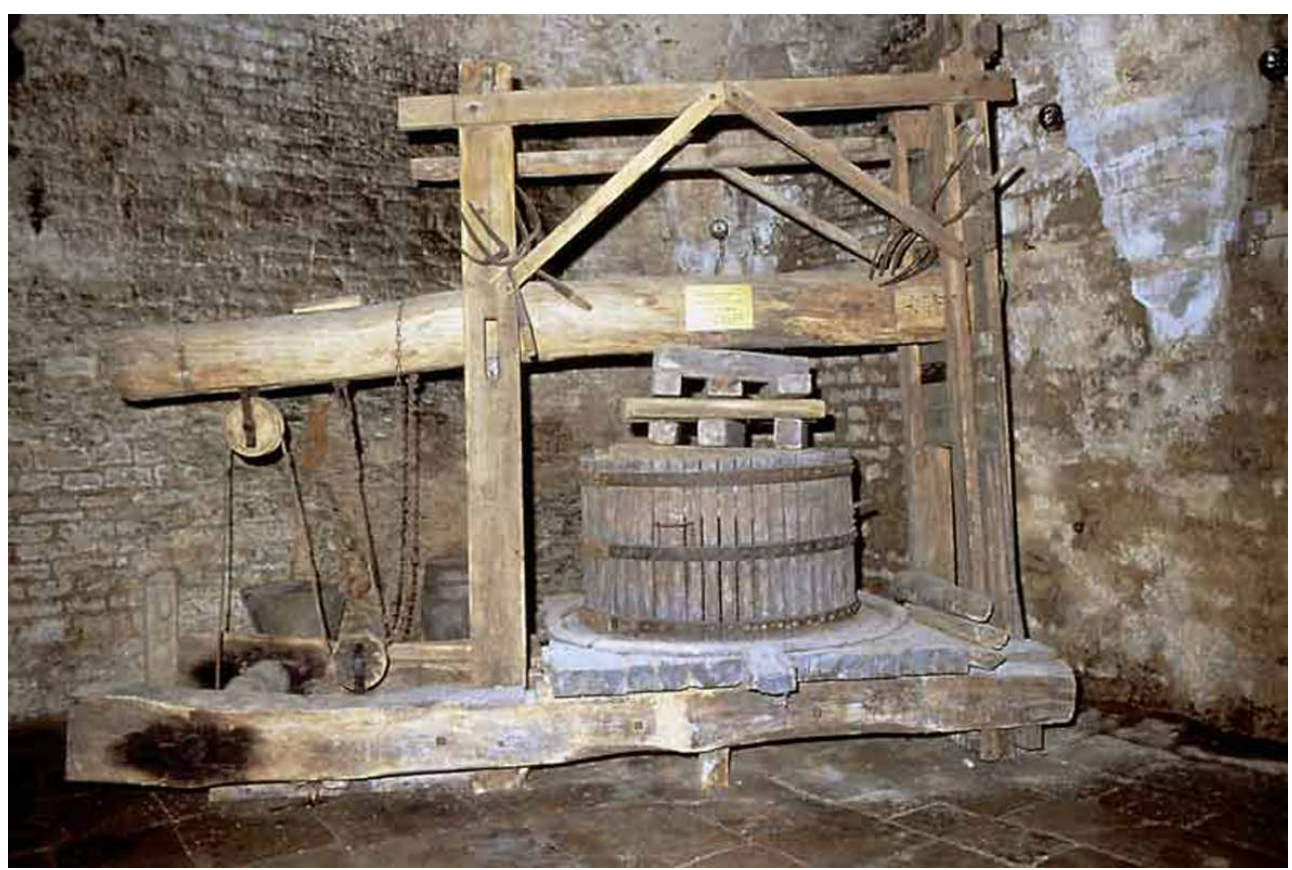

Casse-coué d'Asquins, Yonne, conservé dans une des salles de la mairie de Vézelay. Vue d'ensemble Phot. Inv. J.L. Duthu @ Inventaire général, ADAGP, 2002

\section{Figure 45}

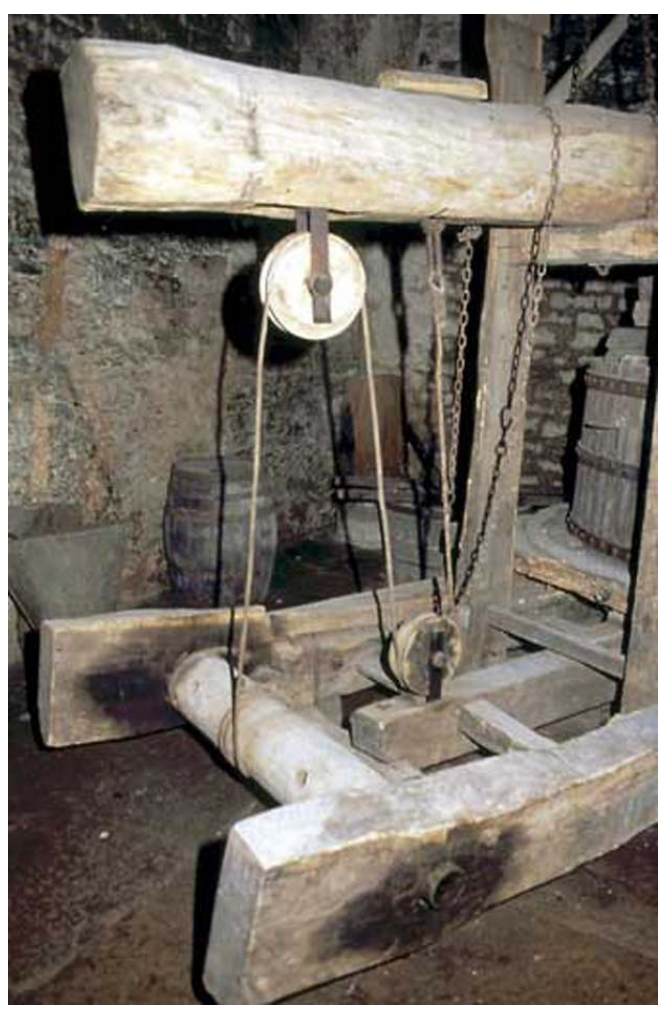

Casse-coué d'Asquins, Yonne, conservé dans une des salles de la mairie de Vézelay. Détail de l'avant du pressoir

Phot. Inv. J.L. Duthu @ Inventaire général, ADAGP, 2002 

domestiques, souvent mobiles, mais aussi les pressoirs métalliques à vis centrale et à coffre, sont toujours très menacés, qu'ils aient été abandonnés au fond des remises et des cuveries ou exposés aux intempéries sur les places de village. 
111 préoccupante. Les conditions actuelles de vinification, le besoin d'espace sans cesse accru, condamnent bon nombre de ces pressoirs dès lors qu'ils ne sont pas spectaculaires et qu'ils n'apportent aucune valeur ajoutée aux exploitations viticoles qui les abritent.

\section{BIBLIOGRAPHIE}

Abric, L. Les vins de Bourgogne au XIX ${ }^{\mathrm{e}}$ siècle : aspects économiques, sociaux, culturels. Précysous-Thil, 1993.

Beck, P. « Dans les vignes du duc de Bourgogne. Le Clos de Chenôve au XIV ${ }^{\mathrm{e}}$ siècle », Histoire et sociétés rurales, $\mathrm{n}^{\circ} 5,1996$.

Beck, P., Canat, C., Lauvergeon, B. et alii. Le Clos de Chenôve ; La cuverie et les pressoirs des ducs de Bourgogne. Histoire, archéologie, ethnologie (XIII ${ }^{\mathrm{e}}-\mathrm{XX}^{\mathrm{e}}$ siècles). Editions du Patrimoine. Edit. Faton, Dijon, 1999 (Images du Patrimoine n 190, Dossier de l'Art hors-série n 1).

Colombet, A. Le folklore de la vigne et du vin en Côte-d'Or. Catalogue du Musée du Vin de Bourgogne à Beaune, Paris, 1965.

Coudor, P. « Les vieux pressoirs de la Côte vigneronne », Comm. de Linguistique et de Folklore de Bourgogne, 1958.

Diderot et d'Alembert. L'Encyclopédie ou dictionnaire raisonné des sciences, des arts et des métiers. Paris, 1751.

Duboeuf, R., Mauge, N. Un pressoir mâconnais : le fouloir de Thomas Révillon (1825). Mâcon, 1984.

Firmin-Didot. Encyclopédie Moderne, 1852.

Gras, P. « La date des pressoirs de Chenosves », Bull. du Syndicat d'initiative de Dijon, avril 1953.

Humbel, X. Vieux pressoirs sans frontières. Paris, 1976.

Lachiver, M. Vin, vignes et vignerons : histoire du vignoble français. Paris, 1988.

Lachiver, M. Dictionnaire du monde rural, les mots du passé. Paris, 1997.

Lagrange, A. Catalogue du Musée du vin de Bourgogne à Beaune. Paris, 1965.

La Nouvelle Maison Rustique. Paris, 1749.

Latour, P. « Recherches sur la marche du progrès dans les pressoirs », Mémoires de la Société

Archéologique de Beaune, 1900.

Lauvergeon, B. « Le pressoir d'Evelle », Canton de Nolay, architecture et oeuvres d'art, catalogue d'exposition de l'inventaire général, Dijon, 2e éd., 1982.

Lauvergeon, B., Portet, F. Architectures, outillages et traditions viticoles. Canton de Tannay (Nièvre). Inventaire Général. Association pour la Connaissance du Patrimoine de Bourgogne, Dijon, 1996. (Images du Patrimoine $n^{\circ}$ 36). 
Lebel, P. « La brisetreuil, date oubliée du calendrier bourguignon », Annales de Bourgogne, t. 23, 1951.

Olivier de Serres, Théâtre d'Agriculture et Mesnage des champs, 1600.

Parain, C. « Typologie des pressoirs pré-industriels », 6e congrès des Sciences anthropologiques et ethnographiques, 1960.

Polge, H. « Généalogie du pressoir », Sté. Arch. Hist. Litt. et Scient., 1967.

Royer, C. Les vignerons, usages et mentalités des pays de vignobles. Paris, 1980.

Vachon, R. Chenôve d'hier (1900-1962). Dijon, s.d.

Violet, E. « Le pressoir à grand point », Annales d'Igé-Mâcon, 1938.

\section{ANNEXES}

\section{Glossaire}

\begin{tabular}{|c|c|}
\hline Terme & Définition(s) \\
\hline Aiguilles & $\begin{array}{l}\text { (esquillettes en } 1400 \text {, clés au XVIII }{ }^{\text {e }} \text { siècle). Petits madriers de bois qu'on dispose dans } \\
\text { les mortaises des jumelles et des fausses jumelles pour immobiliser le levier du } \\
\text { pressoir dans ses différentes positions. (D'après M. Lachiver, c'est aussi, à Lyon, le } \\
\text { nom qu'on donne aux montants verticaux qui soutiennent le chapeau et la roue du } \\
\text { pressoir à vis). }\end{array}$ \\
\hline Cales & $\begin{array}{l}\text { (marres au XIVe siècle). Madriers interposés entre les marcs et le levier. Ils sont } \\
\text { disposés de sorte que la pression transmise par le levier soit régulièrement répartie } \\
\text { sur la vendange. En Roannais, ces plots croisés sont appelés les marchons (M. } \\
\text { Lachiver). La marre, du latin marra, c'est aussi la maille ou meille bourguignonne, } \\
\text { houe à lame pleine. }\end{array}$ \\
\hline Ecrou & $\begin{array}{l}\text { Pièce de bois massive, traversée par la vis. C'est l'écrou qui tire sur le levier. Pour } \\
\text { éviter qu'il n'éclate sous la traction, l'écrou était fait dans un bois noueux, loupe } \\
\text { d'orme ou de noyer. Dans un procès-verbal de } 1560 \text {, l'écrou est appelé creot : ...nous } \\
\text { ont aussi remonstre que la viz et creot du gros treuil est besoing... reffaire tout a neuf } \\
\text { et remettre avant les vendanges (A.D.Côte-d'Or, C } 2137-f^{\circ} 75 \text { ). }\end{array}$ \\
\hline Etiquet & $\begin{array}{l}\text { Bâton ou perche, appelé «bras de serrage » à Chenôve, qui permet d'actionner la vis. } \\
\text { L'extrémité de la perche est engagée dans une mortaise pratiquée à la base de la vis, } \\
\text { dans la Lanterne Les étiquets, en bois de brin, étaient souvent réalisés en frêne, bois } \\
\text { « souple » et résistant. }\end{array}$ \\
\hline Gâteau & $\begin{array}{l}\text { Marc compacté par le pressurage. Sur les gros pressoirs, un marc auquel en le } \\
\text { commençant on donne ordinairement deux piés, ou deux piés \& demi d'épaisseur } \\
(0,65 \mathrm{~m} \text { ou } 0,80 \mathrm{~m}) \text {, se réduit à la fin de la pression à moitié ou un tiers au plus } \\
\text { d'épaisseur...(extrait de l'Encyclopédie, t. XIII, p. 329). }\end{array}$ \\
\hline
\end{tabular}




\begin{tabular}{|c|c|}
\hline Goulotte & $\begin{array}{l}\text { Petite rigole pratiquée à l'extrémité d'une des pièces de la maie pour permettre } \\
\text { l'écoulement du jus. On disait aussi goulerotte à Chenôve (R. Vachon-biblio.). Dans } \\
\text { l'Encyclopédie, on trouve les termes de goulette et de béron, et M. Lachiver donne } \\
\text { pour la Manche celui de bérot. }\end{array}$ \\
\hline Grappine & $\begin{array}{l}\text { Pioche à trois dents utilisée en Bourgogne pour remplir la sapine et le seau avec la } \\
\text { vendange et pour « dépresser » le gâteau de marc sur la maie entre deux pressurages. } \\
\text { Grappin dans le Mâconnais (R. Duboeuf- biblio.). }\end{array}$ \\
\hline Jumelles & $\begin{array}{l}\text { appelées aussi colonnes, dès le XIV }{ }^{\mathrm{e}} \text { siècle. Ce sont les quatre montants verticaux du } \\
\text { bâti d'un pressoir à levier. Elles encadrent la maie. Celles qui sont à l'arrière, à } \\
\text { l'opposé de la vis, portent le nom de jumelles, les deux autres, situées à l'avant, celui } \\
\text { de fausses jumelles. Elles sont assemblées aux pièces transversales du faux chantier et } \\
\text { solidarisées à leur partie supérieure par une traverse dépassante, le chapeau. Les } \\
\text { jumelles sont, en outre, réunies par une entretoise ou une moise. Les fausses jumelles } \\
\text { n'ont pas d'entretoise en raison de la course du levier, mais elles sont solidement } \\
\text { épaulées par quatre contrevents, deux longitudinaux et deux transversaux. Les } \\
\text { contrevents transversaux s'appuient sur le souillard, et les contrevents longitudinaux } \\
\text { sont assemblés aux patins du chantier. Comme sur plusieurs grands pressoirs } \\
\text { bourguignons de même type, comme au Clos de La Perrière, à Fixin, par exemple, la } \\
\text { stabilité transversale des fausses jumelles est renforcée par deux aisseliers assemblés } \\
\text { aux extrémités du chapeau. }\end{array}$ \\
\hline Lanterne & $\begin{array}{l}\text { Les étiquets, en bois de brin, étaient souvent réalisés en frêne, bois «souple " et } \\
\text { résistant. }\end{array}$ \\
\hline Maie & $\begin{array}{l}\text { (matis au XVe siècle, maye ou emoy au XVIII }{ }^{\mathrm{e}} \text { siècle). Plateau du pressoir qui reçoit les } \\
\text { marcs. Il repose sur les chantiers. Il est constitué de pièces juxtaposées serrées par } \\
\text { des coins. Ces derniers sont bloqués dans les entailles du chantier. Les pièces de la } \\
\text { maie sont elles-mêmes entaillées pour former le bassin qui canalise le jus. }\end{array}$ \\
\hline Manteau & $\begin{array}{l}\text { Plateau en bois, généralement en chêne, et souvent circulaire, qui était posé sur les } \\
\text { marcs et sur lequel étaient empilées les cales. }\end{array}$ \\
\hline Sapine & $\begin{array}{l}\text { Petit baquet en bois qui permettait, avec les seaux en bois, de transporter la } \\
\text { vendange du char à la cuve puis de la cuve au pressoir. }\end{array}$ \\
\hline Taisson & $\begin{array}{l}\text { Nom donné aux pièces de bois ou au bloc de pierre destinés à maintenir le pied de la } \\
\text { vis d'un pressoir à levier à taissons ou à cage. Dans le premier cas, les taissons, s'ils } \\
\text { sont en bois, sont profondément enterrés pour résister à l'effort d'arrachement, dans } \\
\text { le second cas, ils sont logés dans une fosse appareillée, la cage, où ils sont solidement } \\
\text { retenus par un assemblage de madriers. Les taissons sont constitués de deux pièces } \\
\text { de bois solidarisées par des traverses moisées (comme à Champvallon), ou par la } \\
\text { fourche naturelle d'un chêne (à Fixin, au Clos de La Perrière, par exemple). }\end{array}$ \\
\hline $\begin{array}{l}\text { Vin de } \\
\text { goutte }\end{array}$ & $\begin{array}{l}\text { Vin rouge, prélevé par soutirage, qui résulte d'une première fermentation en cuve de } \\
\text { la vendange (d'après X. Humbel). Dans le catalogue du musée du vin de Beaune, A. } \\
\text { Lagrange parle de vin de pied, la vendange étant foulée en cuve par des hommes nus } \\
\text { qui y entraient jusqu'aux aisselles. Dans l'Encyclopédie on trouve l'expression vin de } \\
\text { cuvée. }\end{array}$ \\
\hline
\end{tabular}




\begin{tabular}{|l|l|}
\hline $\begin{array}{l}\text { Vin de } \\
\text { presse }\end{array}$ & Jus qui résulte du premier pressurage. \\
\hline $\begin{array}{l}\text { Vin de } \\
\text { rebêche }\end{array}$ & $\begin{array}{l}\text { Les marcs compactés, mais non encore asséchés, devaient être aérés. Ils étaient } \\
\text { retournés, " rebêchés » et recoupés avant de subir un nouveau pressurage. Ces } \\
\text { pressurages successifs produisaient un vin de moindre qualité que l'on appelait vin } \\
\text { de rebêche (J.Y. Drouin), vin d'égout puis vin de recoupage avant la dernière pressée } \\
\text { qui donnait un médiocre vin de taille (X. Humbel). Cette piquette est encore appelée } \\
\text { dans l'Encyclopédie vin de dernière goutte. }\end{array}$ \\
\hline Vis & $\begin{array}{l}\text { La vis, qui peut atteindre 35 cm de diamètre sur un grand pressoir, comme à } \\
\text { Chenôve, était une des pièces les plus sujettes à la rupture en raison des forces de } \\
\text { traction et de torsion auxquelles elle était soumise pendant la presse. Les vis étaient } \\
\text { d'ailleurs régulièrement remplacées (voir infra). Le pied de la vis, fixé au contrepoids } \\
\text { par un collet, et la lanterne dans laquelle on glissait l'étiquet, étaient } \\
\text { particulièrement exposés à la rupture. Pour en limiter les risques, les vis étaient } \\
\text { généralement faites dans un bois «plus gras » que le chêne, comme le cormier, le } \\
\text { chêne trop «nerveux » se fendant facilement. Dans l'Encyclopédie il est conseillé au } \\
\text { maître pressureur de ne point trop laisser sortir la vis de son écrou, de peur qu'elle } \\
\text { ne torde : c'est une précaution, précise-t-on, qu'il faut avoir pour toutes sortes de } \\
\text { pressoirs. (Extrait de Le Clos de Chenôve..., Images du Patrimoine, 1999, n 190, p. 29 } \\
\text { et 30.) }\end{array}$ \\
\hline
\end{tabular}

\section{NOTES DE FIN}

1. Informations communiquées par Jacques Guillaume, Service régional de l'Inventaire de Lorraine.

2. La vis en bois du pressoir antérieur du Clos de Chenôve a toutefois été remplacée par une vis en fer, solidarisée à un volant en bois à rayons et poignées de métal, mais la lanterne en bois a curieusement été conservée.

\section{RÉSUMÉS}

Chrono-typologie des grands pressoirs bourguignons pré-industriels. Cet article s'inscrit dans le cadre des recherches qui ont été réalisées à la DRAC par les services de l'Inventaire régional et de l'Ethnologie sur le patrimoine viti-vinicole bourguignon. Outre conférences et articles, ces enquêtes conjointes ont donné lieu, notamment, à deux publications de la collection des Images du patrimoine du Ministère de la Culture. La première, en 1996, a présenté l'architecture, l'outillage et les traditions viticoles du canton de Tannay (Nièvre) ; la seconde, réalisée en 1999, fut consacrée à l'histoire, à l'archéologie et à l'ethnologie de la cuverie et des pressoirs du Clos de Chenôve. Avec l'architecture vigneronne et le mobilier vinaire, ces études thématiques nous ont permis de repérer, et parfois de découvrir, un pourcentage significatif des grands pressoirs préindustriels qui subsistent aujourd'hui en Bourgogne. Plusieurs de ces grandes machines ont d'ailleurs été l'objet tout récemment, à notre demande, d'une inscription à l'Inventaire supplémentaire des Monuments historiques. Le dessein de cet article est de faire un inventaire rapide de ce patrimoine trop longtemps négligé, d'en proposer une typologie et de tenter d'en saisir l'évolution chronologique. Nous analysons les trois grands types, pressoirs à levier, à grand point et à vis centrale, mais aussi les principales variantes qui ont été utilisées sur l'ensemble du 
territoire bourguignon, du Mâconnais au Chablisien, de la fin du Moyen-Age à la période contemporaine, certains pressoirs ayant en effet fonctionné jusque dans les années 1950. Cette étude thématique pose, évidemment, de nombreuses questions qui sont liées, en particulier, à la sauvegarde de ces mastodontes désormais inutiles et encombrants. Se pose aussi la question récurrente de leur datation. Les documents disponibles, quand ils existent, sont souvent difficiles à exploiter; aussi le seul moyen fiable d'avoir une indication chronologique reste-t-il, dans la plupart des cas, l'analyse dendrochronologique qui peut fournir, pour certaines pièces de bois, la date d'abattage de l'arbre.

Chronotypology of the important preindustrial Burgundian wine-presses of Burgundy. This article is part of the research undertaken by the Inventaire Général and Ethnology departments at the Direction régionale des Affaires culturelles of Burgundy on the Burgundian viti-and vinicultural heritage. Two studies have already been published; the first in 1996 about architecture, tools and traditions in the Tannay area (Nièvre); the second, in 1999, about the history, archeology and ethnology of the vats and wine-presses at the Clos de Chenôve (Côted'Or), they have shown that a significant percentage of important wine-presses of the industrial era still exists in Burgundy. Several have been recently registered as important cultural properties (Inventaire suppl. des Monuments historiques). Our object here is to list briefly these wine presses, to draw up a typology and to understand their evolution. Three main types can be described: wine presses with lever, with lever and shaft and with a central screw. Variations are also to be considered and have been used from the Middle Age until 1950. This study raises questions about the preservation of such machines but also how to date them, since the only sources available are difficult to exploit, hence, dendrochronological analysis is often the most reliable method.

\section{INDEX}

Mots-clés : Bourgogne, vin, vigne, viticulture, pressoir à levier, pressoir à grand point, pressoir à vis centrale, pressoir domestique, étiquet, roues de presse, treuil, cabestan, taissons, roues à perroquet, roue à écureuil, contrepoids mobile

\section{AUTEUR}

\section{BERNARD LAUVERGEON}

Conservateur du patrimoine, Service régional de l'Inventaire, Direction régionale des affaires culturelles de Bourgogne. bernard.lauvergeon@culture.gouv.fr 